\title{
WestVirginiaUniversity
}

THE RESEARCH REPOSITORY @ WVU

Graduate Theses, Dissertations, and Problem Reports

2019

\section{Application of Lidar to 3D Structural Mapping}

\author{
Bertrand Gaschot \\ West Virginia University, bpg0002@mix.wvu.edu
}

Follow this and additional works at: https://researchrepository.wvu.edu/etd

Part of the Geology Commons

\section{Recommended Citation}

Gaschot, Bertrand, "Application of Lidar to 3D Structural Mapping" (2019). Graduate Theses, Dissertations, and Problem Reports. 4111.

https://researchrepository.wvu.edu/etd/4111

This Thesis is protected by copyright and/or related rights. It has been brought to you by the The Research Repository @ WVU with permission from the rights-holder(s). You are free to use this Thesis in any way that is permitted by the copyright and related rights legislation that applies to your use. For other uses you must obtain permission from the rights-holder(s) directly, unless additional rights are indicated by a Creative Commons license in the record and/ or on the work itself. This Thesis has been accepted for inclusion in WVU Graduate Theses, Dissertations, and Problem Reports collection by an authorized administrator of The Research Repository @ WVU. For more information, please contact researchrepository@mail.wvu.edu. 


\title{
Application of Lidar to 3D Structural Mapping
}

\author{
Bertrand Gaschot
}

Thesis submitted to the Eberly College of Arts and Sciences at West Virginia University in partial fulfillment of the requirements for the degree of

\section{MASTER OF SCIENCE}

in

\section{GEOLOGY}

Jaime Toro, Ph.D., Chair

Dengliang Gao, Ph.D.

Aaron Maxwell, Ph.D.

Department of Geology and Geography

Morgantown, West Virginia

2018

Keywords: Lidar, Smoke Hole Canyon, Structure, 3D Mapping, Kinematic Modeling

Copyright 2019 Bertrand Gaschot 


\section{ABSTRACT \\ Application of Lidar to 3D Structural Mapping}

\section{Bertrand Gaschot}

The rugged, densely forested terrain of the West Virginia Appalachian Valley and Ridge Province has made it difficult for field-based studies to agree on the structure of the highly deformed Silurian-Devonian cover strata. In this study, we demonstrate a 3D approach to geologic mapping utilizing the structural information revealed in a "bare-earth" 1-m Lidar DEM of the Smoke Hole Canyon. The completed 3D map was integrated with kinematic forward modeling carried out in $\mathrm{MOVE}^{\mathrm{TM}}$ to provide information on the parameters required to form the major structures observed. Additionally, land surface attributes generated using geomorphometric analysis of the Lidar allowed for better mapping of smaller scale structures and specific outcrops.

Our kinematic reconstructions and 3D models show that the Cave Mountain Anticline can be produced with Trishear-style deformation for fault-propagation folds. Also, the depth to detachment of the Cave Mountain thrust shallows along strike to the north and south, indicating that lateral ramps are required from the Martinsburg to the Juniata Formation. Additionally, steeper backlimb dips indicate that the thrust ramp angle increases from $30^{\circ}$ to $45^{\circ}$ moving southward. To the north, the Cave Mountain Anticline splits in to two, indicating that the main thrust plane is branching at depth, resulting in an imbricated-thrust geometry. Kinematic reconstructions of the shorter wavelength folds west of Cave Mountain show that they can be modeled using detachment folding algorithms, however they must form above a shallower detachment than previously interpreted, within the shales of the Silurian Rose Hill Formation. 


\section{Acknowledgements}

I would like to thank:

My committee for their advice and support throughout this project.

The WVU G\&G Department for fieldwork and research funding through department grants.

My fellow graduate students for the academic and moral support throughout my time here at WVU.

Dr. Jaime Toro for the opportunity to work with this dataset and help with the project.

Dr. Ryan Shackleton help conceive the project and fund the acquisition of the Lidar data.

We thank Petex and Midland Valley Corp for donating the academic license of 3DMOVE to West Virginia University which made this project possible. 


\section{Table of Contents}

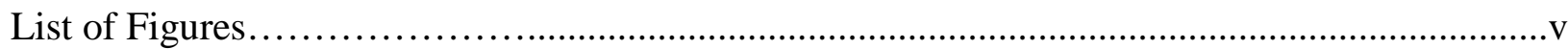

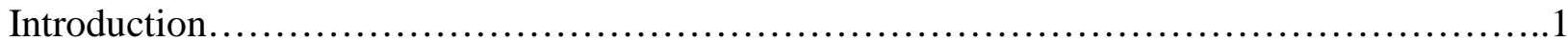

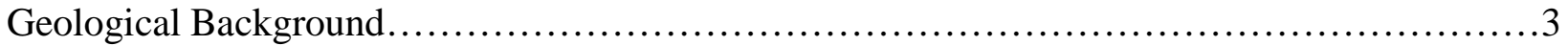

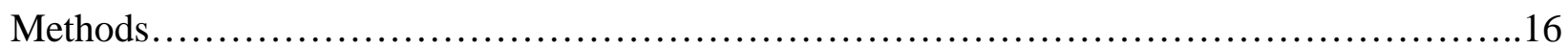

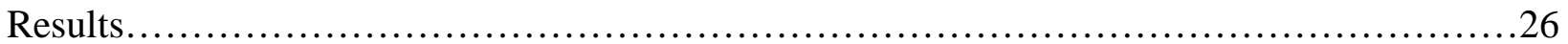

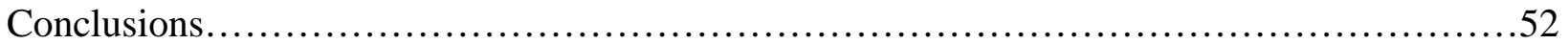

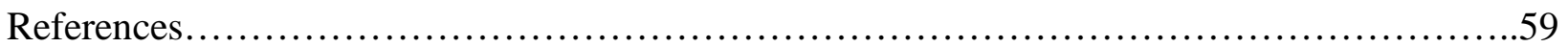

Appendix.......................................................................62 


\section{List of Figures:}

Figure 1: Smoke Hole location map......................................................

Figure 2: Geologic map of the Smoke Hole............................................6

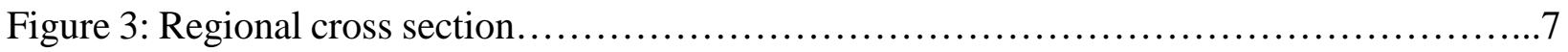

Figure 4: Gerritsen and Sites map and cross section comparison..............................

Figure 5: Stratigraphic column of exposed formations at the Smoke Hole.......................12

Figure 6: General Stratigraphy of the Central Appalachian V\&R Province......................13

Figure 7: Cave Mountain Anticline Lidar Overview........................................15

Figure 8: Generalized 3D mapping workflow........................................... 18

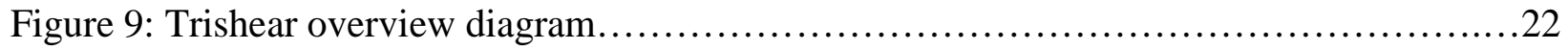

Figure 10: Heterogeneous vs homogenous Trishear........................................23

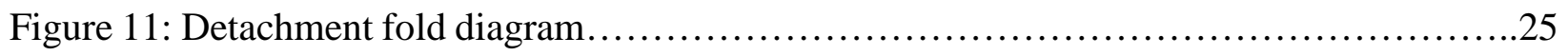

Figure 12: DEM map drape and structural measurements................................28

Figure 13: 3D map Google Earth screenshot............................................31

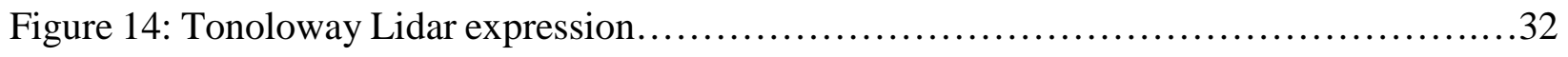

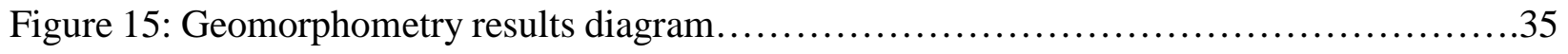

Figure 16: Depth to detachment Lidar comparison at Big Bend...............................39

Figure 17: Depth to detachment Lidar comparison at Eagle Rock.............................41 
Figure 18: Kinked Forelimb Lidar comparison

Figure 19: 3D view of Cave Mountain Thrust............................................44

Figure 20: Cross section through Big Bend..........................................47

Figure 21: Cross section through Eagle Rock.......................................48

Figure 22: Cross section through northern portion of the Smoke Hole.......................49

Figure 23: Screenshots of 3D pdf exports..........................................51

Figure 24: 3D geologic map at Big Bend..........................................54

Figure 25: Outcrop prediction using 3D model and Lidar DEM............................55

Figure 26: Rule of V's demonstration using Lidar and 3D model ..........................58 


\section{INTRODUCTION}

Airborne Lidar (light detection and ranging) derived digital elevation models can provide excellent 3D renditions of both natural and man-made objects (Zhang, 2006). In the earth sciences, Lidar technology is primarily used in geomorphological studies to map surficial features such as landslides or coastal changes (Ardizzone et al., 2007; Wozencraft et al., 2006). Lidar use for structural analysis is usually limited to terrestrial systems for scanning a single outcrop-scale feature (Bellian, 2005; Buckley et al., 2008), aerial systems for detecting recent faults (Arrowsmith, 2009), or to help constrain mapping in the same way that aerial photos were used in the past. Pavlis et al. (2011), first noted that bedrock bedding traces were visible in a 1-m resolution, bare-earth Lidar DEM and used them to map surface ruptures in Southern Alaska. Utilizing MOVE, they used the Lidar DEM to map the bedrock structure in an area of poor exposure and developed a structural processing workflow for the use of airborne Lidar in structural analysis.

Although the work by Pavlis et al. (2011) helped to establish a new application for airborne Lidar in the field of structural geology, the study area was located in a poorly vegetated artic region. We believe that in regions with heavy forest cover, high relief, and complexly deformed strata such as the Central Appalachian fold-and-thrust belt, the Lidar can be leveraged to provide a level of structural insight that is not possible to achieve by traditional methods. In this study, we describe how a 1-m resolution Lidar DEM was used, in combination with fieldwork and modern kinematic modeling and mapping software, to extract structural information and enhance understanding of bedrock structure in an area where field studies are notoriously difficult and contradictory. Furthermore, we utilize the forward modeling modules and 3D capabilities of MOVE to build 
balanced cross sections and a 3D structural model, providing a way to learn about how structures into the subsurface. 


\section{GEOLOGIC BACKGROUND}

The Smoke Hole Canyon consists of a 10 mile-long northeast-trending gorge located within the Central Appalachian Valley and Ridge Province of Grant and Pendleton counties, eastern West Virginia (Fig 1). The is dissected by the South Branch River, creating spectacular exposures of the complexly deformed cover sequence of the West Virginia Valley and Ridge Province. The rocks exposed here overlie the eastern flank of the Wills Mountain anticline, located just east of the Allegheny structural front. This Silurian-Devonian package is composed of thin-bedded alternating clastic and carbonate rocks, deposited in response to tectonic loading events along the mid-Paleozoic Appalachian active margin coupled with sea level changes. In general, the cover is dominated by thrust faults and folds with wavelengths on the order of 1-5 km. These structures have been the source of controversy as both fold and fault dominated geometries have been proposed by different authors (Sites, 1971; Kulander and Dean, 1986; Mitra, 1986; Ferrill, 1986; Gerritsen, 1988).

The local structure of the Smoke Hole canyon can be separated in to two structural domains. The eastern margin is dominated by the Cave Mountain Anticline (Fig 2), a NE-SW trending, doublyplunging fold with a vertical to overturned forelimb and gently dipping backlimb (25-45 $\mathrm{SE}$ ). This large fold spans the entire length of the canyon and continues on to the south for several miles. In the center of the study area the core of the anticline is exposed with the resistant Tuscarora Sandstone making up Big Bend, a popular camping and fishing location. On the southern end of the field area the fold is particularly well exposed, and a resistant portion of the steep forelimb made up of Oriskany Sandstone creates the spectacular cliffs of Eagle Rock (Fig 2). The western portion of the study area is dominated by many upright, symmetrical, 100-500 m wavelength folds, the largest of which is the Peacock Cave Anticline (Fig 2). There are also a couple relatively low- 
displacement thrusts exposed at the surface in the southern half of the canyon between Big Bend and Eagle Rock. North Fork Mountain makes up the western boundary of the study area and is part of the gently SE dipping backlimb of the Wills Mountain Anticline, which marks the location of the Allegheny Structural Front. The cliffs at the crest of North Fork Mountain are held up by the highly resistant Tuscarora Sandstone.

Sites $(1971,1973)$ carried out the first detailed mapping and structural analysis study of the cover sequence within the Smoke Holes. Sites' interpreted numerous thrust faults in the cover sequence, with 500 to $1000 \mathrm{~m}$ spacing, displacements of 100 to $600 \mathrm{~m}$, stemming from a detachment in the Ordovician Martinsburg Formation. Cross sections by Sites show deformation in the cover sequence dominated by imbricated thrust faults dipping steeply $\left(50-55^{\circ}\right)$ to the southeast with several asymmetrical hanging wall anticlines formed by footwall drag. Sites' interpretation also includes one major back-thrust near Big Bend campground (Fig 3), as well as a set of younger EW trending sinistral strike-slip faults which offset thrusts. Most importantly, when the idea of faultdominated cover deformation converged in the 1980’s (Dean, 1986; Mitra, 1986), Sites’ (1971) work at the Smoke Holes provided data to support the hypothesis. 
Gerritsen (1988) originally intended to investigate finite strain in the heavily faulted cover sequence in West Virginia using the map of the Smoke Hole area produced by Sites $(1971,1973)$. However, in November of 1985 a catastrophic flood greatly reshaped the South Branch of the Potomac River in the Smoke Holes, exposing bed rock in both channel floors and cut banks. Consequently, Gerritsen (1988) found many exposed syncline hinges which had previously been mapped as thrust faults, and interpreted a structural style dominated by folds that were not cut by faults at the surface.

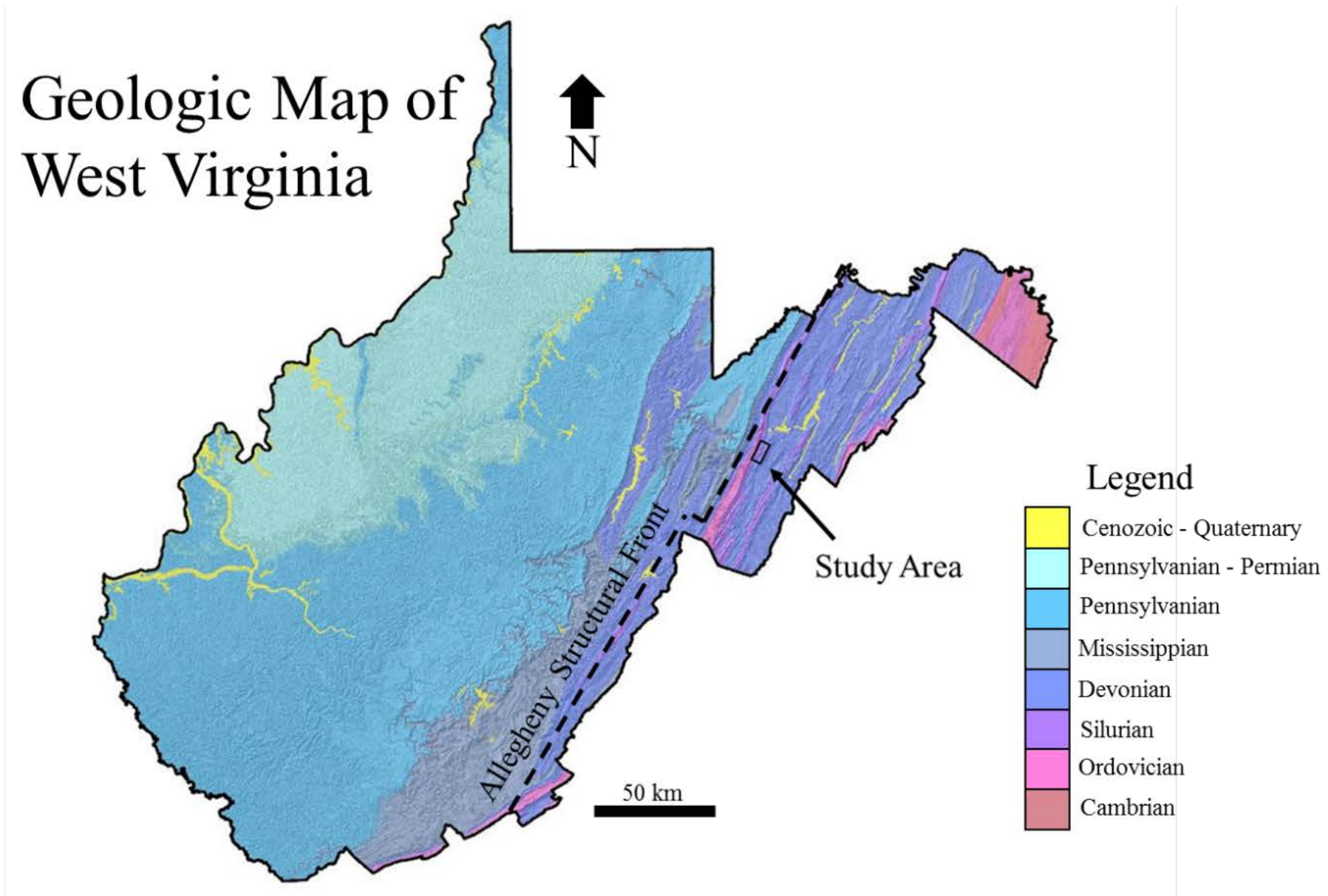

Figure 1: Location map of the study area. The Smoke Hole Canyon lies on the border between Grant and Pendleton counties, just east of the Allegheny Structural Front (Modified from West Virginia Geological and Economic Survey). 
Geologic Map of the Smoke Hole Canyon

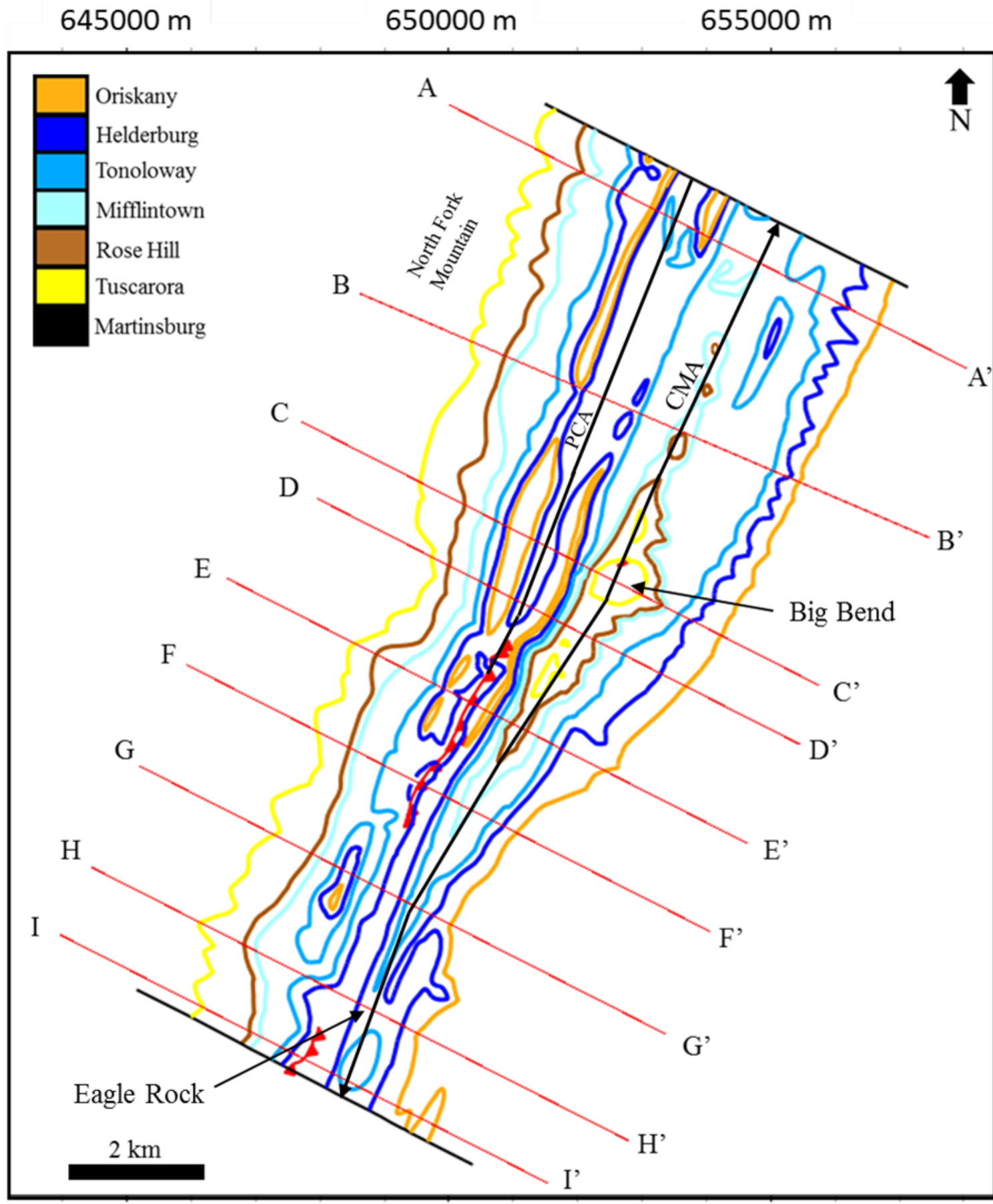

$4310000 \mathrm{~m}$

$4305000 \mathrm{~m}$

$4300000 \mathrm{~m}$

Figure 2: Simplified geologic map of the Smoke Hole Canyon. (CMA: Cave Mountain Anticline; PCA: Peacock Cave Anticline) 


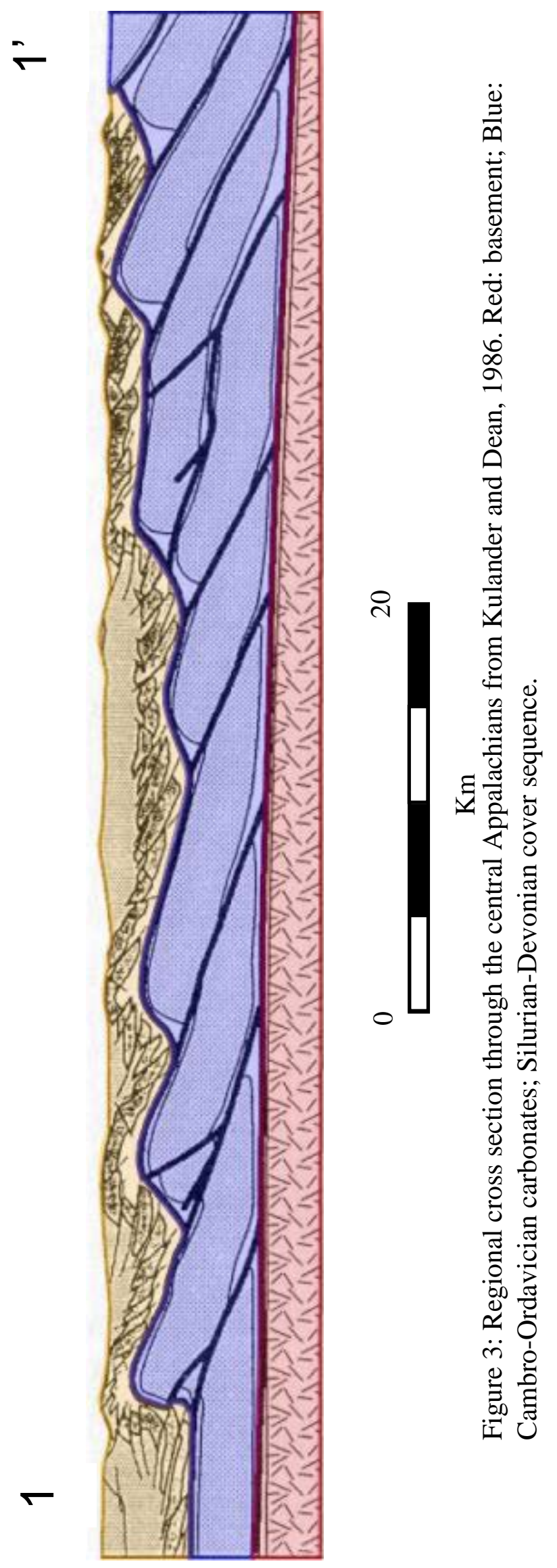




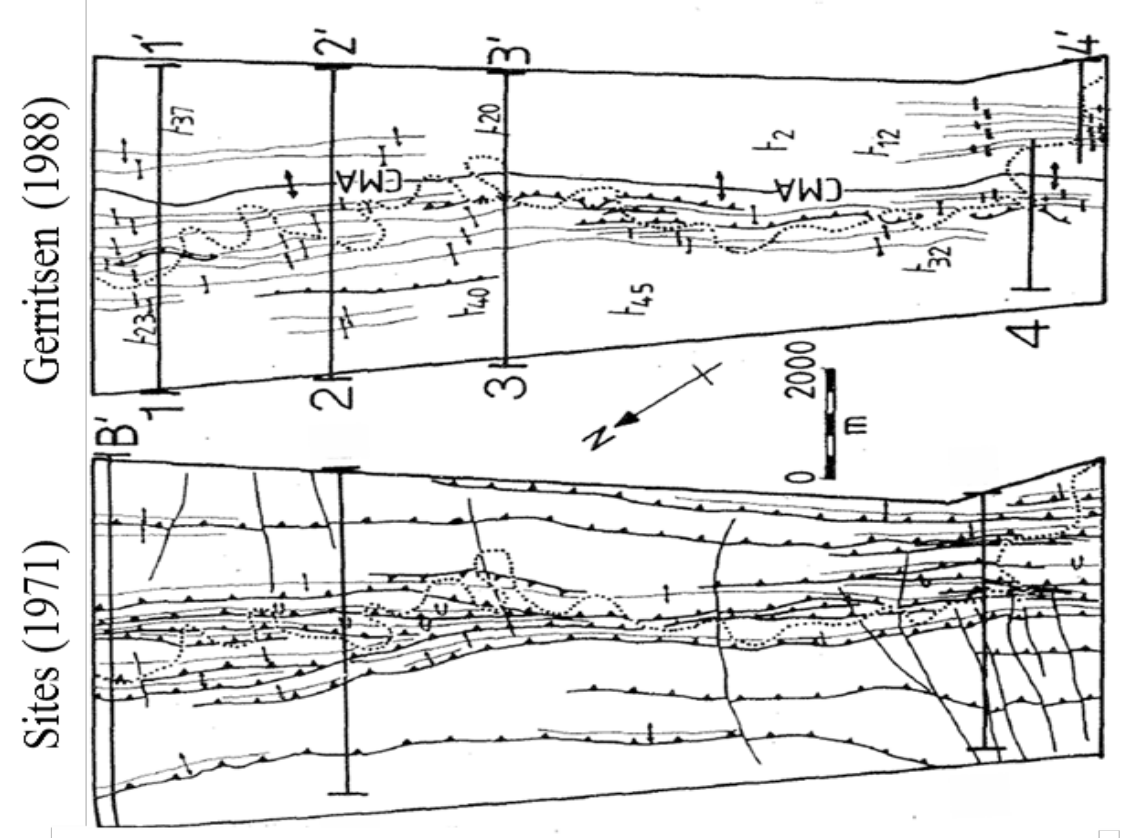

듬

คิ

$\mathbb{3}$

.

尺)

。

氙

몽

อั

ิิ
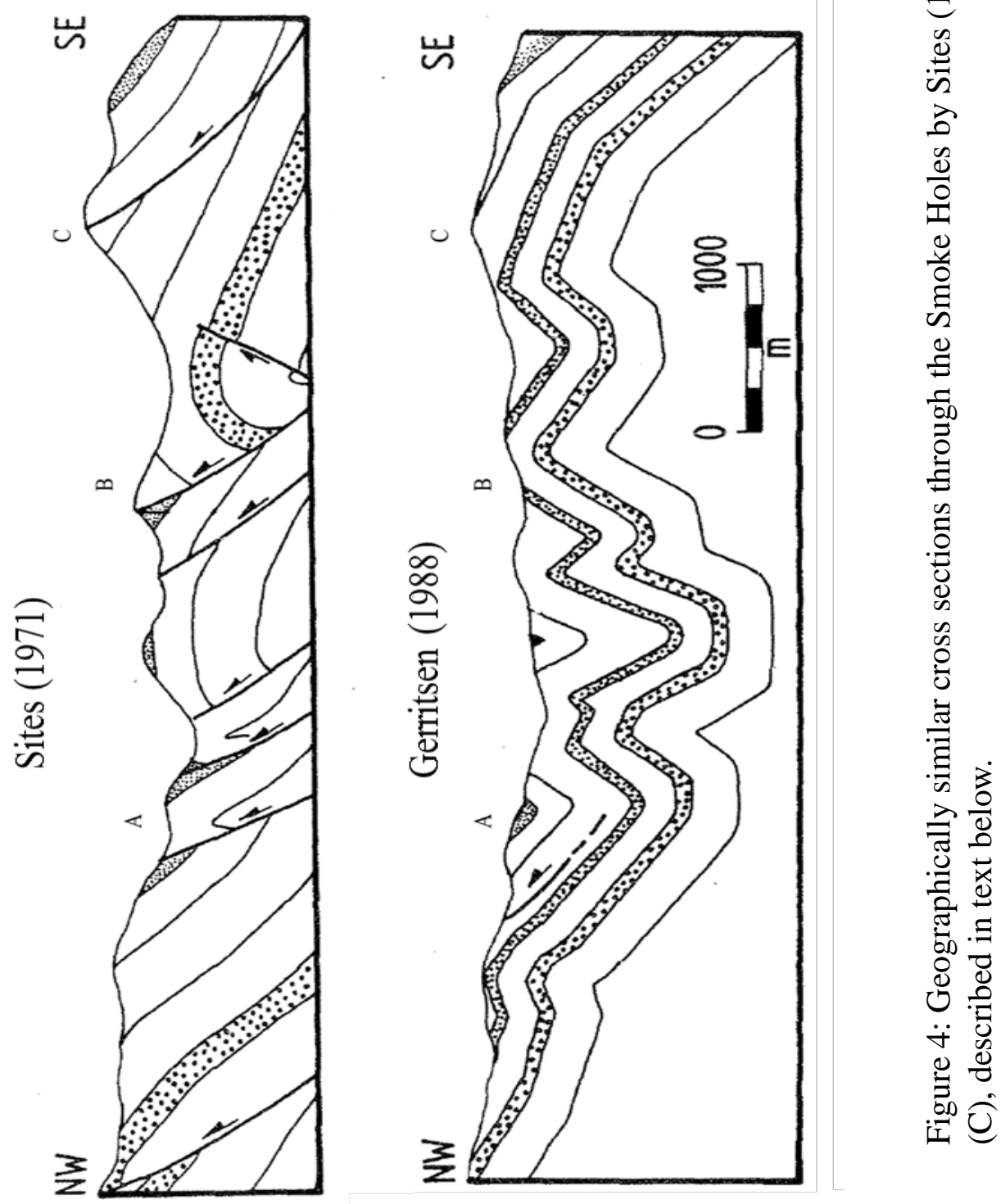
Points (A), (B), and (C) in Figure 4 represent locations along geographically similar cross sections where Sites' (1971) and Gerritsen (1988) came to different structural interpretations, both at the surface and in the subsurface. At point (A) Sites' (1971) observed a repeat of the Oriskany and Helderburg at the surface and interpreted three high-angle thrusts spaced about 500 m apart with 300 m of displacement. Gerritsen (1988), observed no repeat of Oriskany across strike and interpreted a syncline with a single thrust which thickens the Tonoloway formation. At point (B) Sites' (1971) interpreted two high angle thrusts with $500 \mathrm{~m}$ spacing, as well as a back thrust offsetting and raising the Tuscarora sandstone in the subsurface. In contrast, Gerritsen (1988) interpreted a folded anticline-syncline pair. At point (C) Sites' (1971) interpreted a thrust causing the duplication of the Helderburg and Tonoloway formations. Gerritsen (1988) observed no duplication and interpreted the normal stratigraphic sequence dipping gently south-east, making up the gentle back-limb of the Cave Mountain anticline.

Several other structural styles have been proposed by other authors in more regional interpretations of the Appalachian Valley and Ridge. Mitra (1986) proposed a linked duplex system in which thrust faults have fairly uniform displacements, and the roof and floor detachment are parallel. Folds of various sizes form due to mechanical differences of the various lithologies in the cover.

Kulander and Dean (1986) suggested a cover geometry dominated by short-wavelength, asymmetrical, and overturned folds, coupled with forelimb and backlimb thrust faults. In contrast to Mitra (1986), they did not classify the Devonian shales as a major detachment horizon, instead interpreting various incompetent units within the cover as possible detachment zones for both linked and isolated thrusts. Fold style in the cover was also linked to mechanical differences of the various lithologies. 
Ferrill (1987) conducted a study in an area only $8 \mathrm{~km}$ from a cross section produced by Kulander and Dean (1986), using gravity data to model the structure of the deep Cambrian-Ordovician duplexes. Ferrill's interpretation of the cover sequence consisted of a combination of fault-bend and fault-propagation folds with a cover geometry made up of kink and lift-off folds. In that study, no map-scale faults were observed. 


\section{Stratigraphy}

The stratigraphy exposed at the Smoke Holes is made up of an approximately 655 meters (Fig 5) sequence of interlayered Silurian and Devonian carbonate and siliciclastic rocks. Mechanical differences between the various lithologies play an important role in the scale and style of folding that occurs during deformation. The sequence is bounded by two resistant sandstones, the Silurian Tuscarora and Devonian Oriskany formations which form steep NE-SW-trending ridges. Other notable formations include the Helderberg Group and Rose Hill formations, which contain mechanically weaker shaley units and serve as detachment horizons for thrust faults in some interpretations (Gerritsen, 1988). 


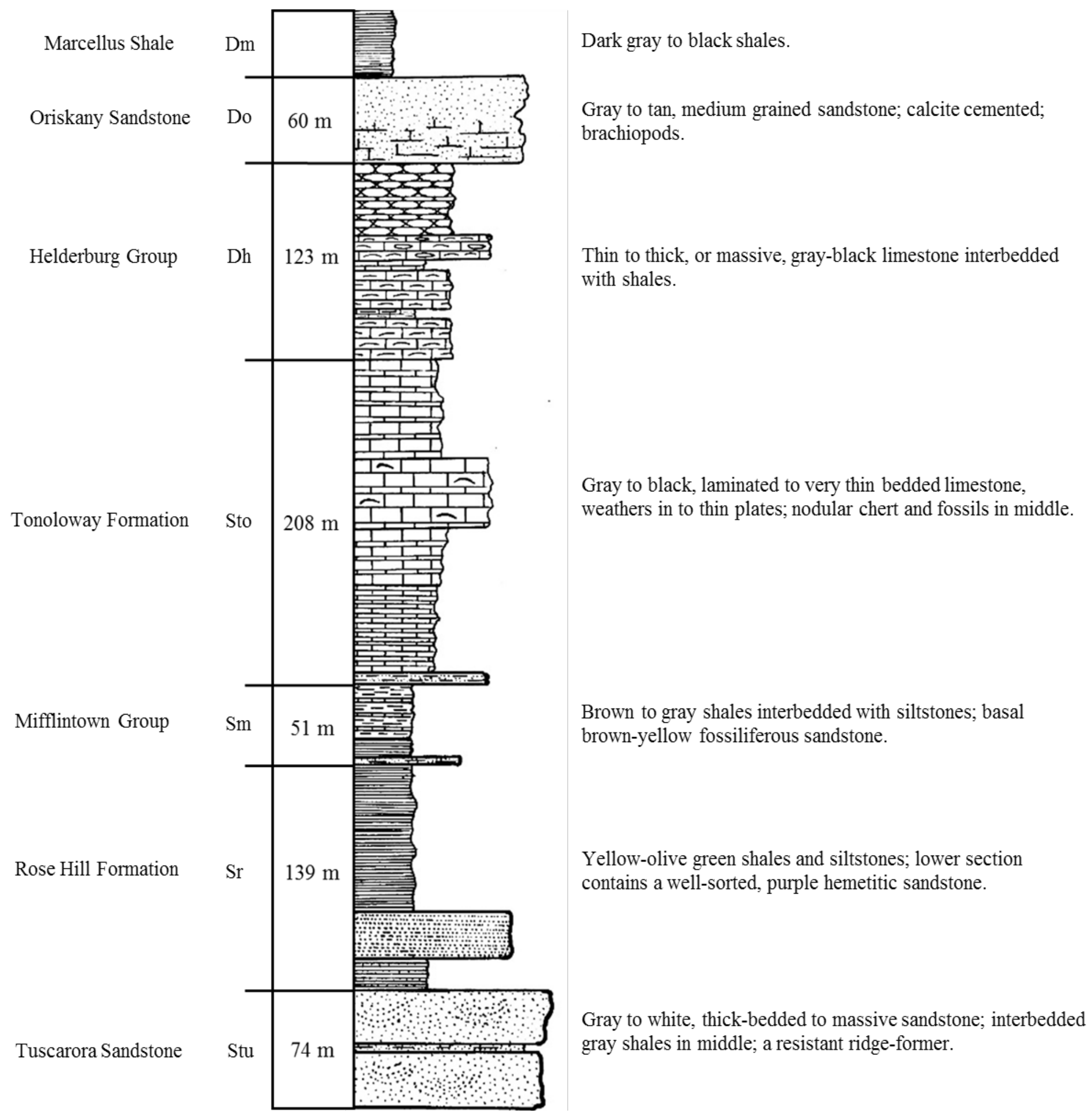

Figure 5: Stratigraphy exposed at the Smoke Hole Canyon, modified from Gerritsen (1988). 


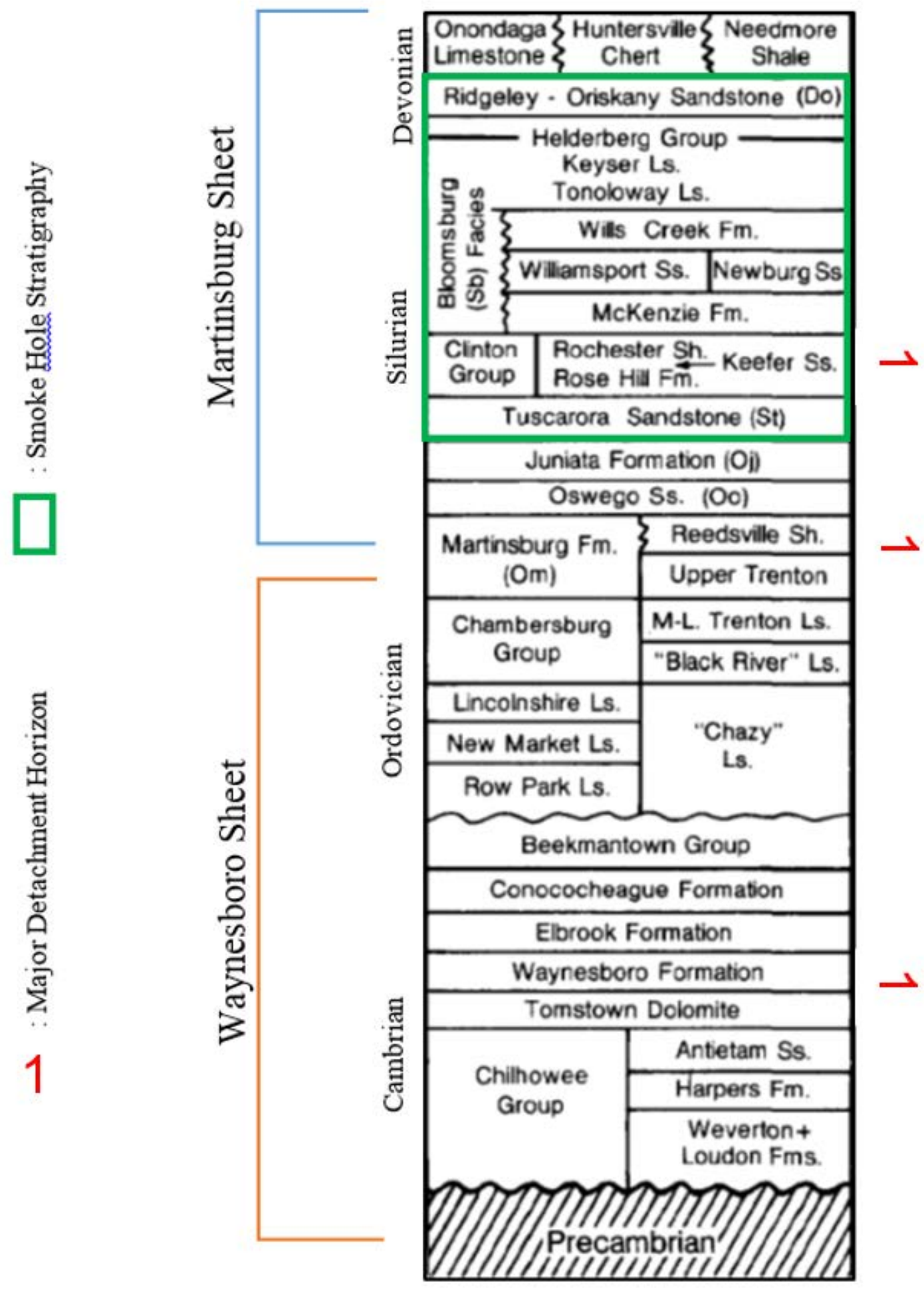

Figure 6: General stratigraphy of the Waynesboro and Martinsburg sheets in the Central Appalachian Valley and Ridge Province, modified from Kulander and Dean, 1986 


\section{Recent Developments: Airborne Lidar}

In the winter of 2015, new high resolution topographic data on the Smoke Hole area was collected using an airborne Lidar system. The collection flight was flown during the leaf-off season at approximately 4,000-ft above ground level with Pulse Rate Frequency (PRF) of 70,000Hz; Scan Frequency of 35Hz; Scan Angle of 18-degrees half-angle (36-degree full field of view). The West Virginia University Natural Resource Analysis Center (WVU NRAC) post-processed the raw point cloud data, removing the non-ground returns and generating a 1-meter "bare-earth" digital elevation model (Zhang et al., 2003; Sithoe et al., 2004). Opening the DEM in MOVE allows for a spectacular 3D rendition of the canyon, which can be enhanced by utilizing surface analysis tools. The effectiveness of the Lidar DEM in revealing bedrock structure is illustrated below (figure) though a dip distribution color overlay. 


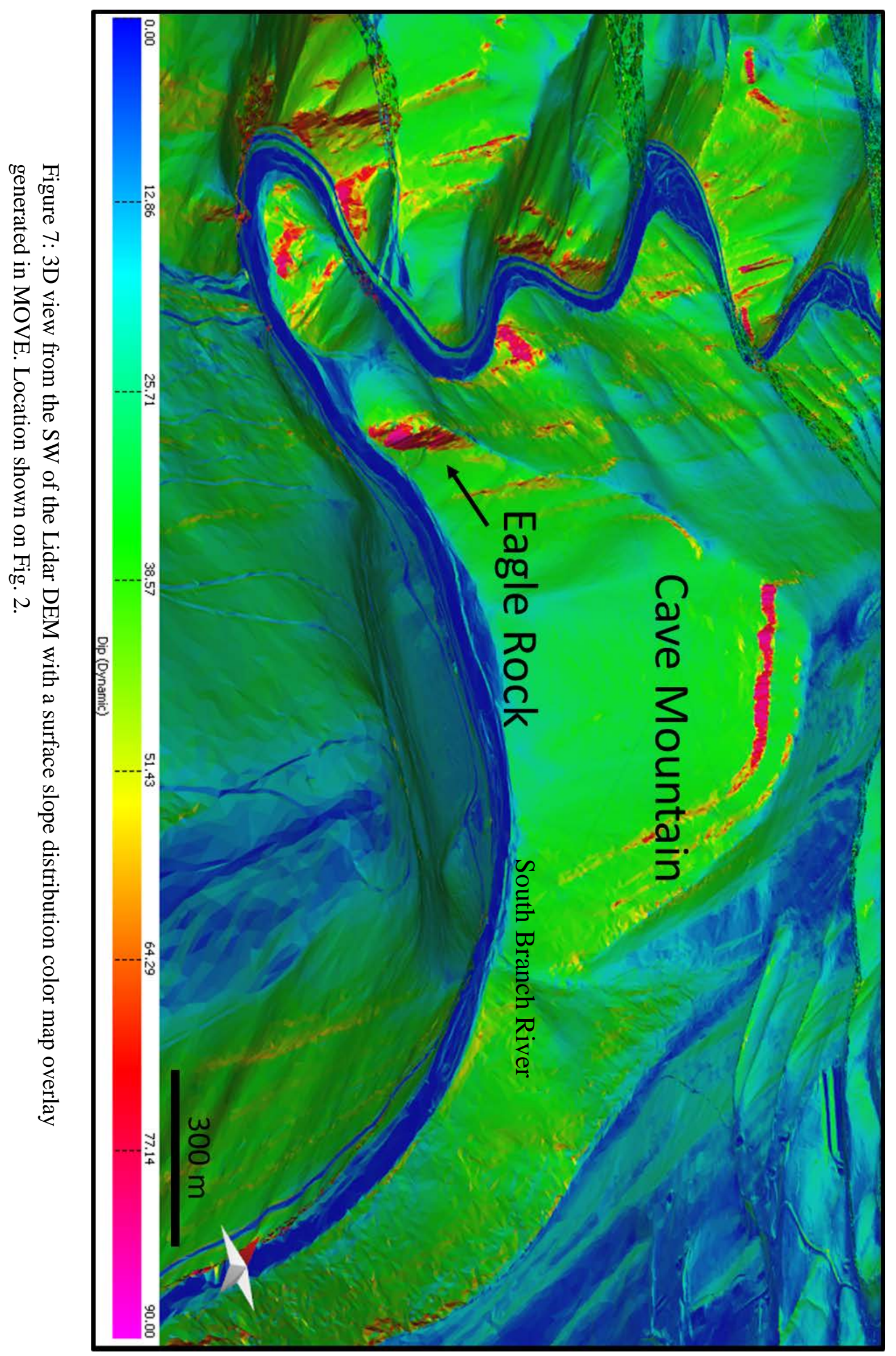




\section{METHODS}

\section{D Geological Mapping with Lidar}

Given the right set of geological and environmental conditions, 1-m resolution Lidar DEM's can capture bedrock features such as bedding planes and geologic structures in 3D (Pavlis et al., 2011). Furthermore, regions with wet climates, dense forest cover, and steep terrain which make field studies difficult can maximize the information gained from the "bare-earth” DEM by acquiring the Lidar during the leaf-off season. Utilizing the existing geologic maps draped over the Lidar DEM and field work we set out to create a 3D geological map in MOVE, modified from the work of Gerritsen (1988). The Smoke Hole area is particularly well suited for this approach because the topography is strongly controlled by the morphology of resistant beds. Many of the mountain slopes are the dip slope of bedding planes.

3DMOVE ${ }^{\mathrm{TM}}$ is a high-end structural modeling software developed by Midland Valley Corporation and Petroleum Experts. Although it was primarily designed for the oil and gas industry, MOVE has applications in many fields, including mining, geothermal, geotechnical engineering, and radioactive waste management, thanks to the wide range of datatypes which can be incorporated. Additionally, it is particularly powerful for 3D mapping as it contains utilities well suited for working with surficial geologic data. The 3D viewer (Fig 7) provides a huge advantage compared to the traditional 2D viewer of ESRI's ArcMap and GIS software, and allows the user to manipulate natural attributes such as sun azimuth, helping reveal features such as bedding planes or folds which may be hidden or faint due to shade direction. MOVE also allows the user to work directly with, and on the DEM. This includes bed tracing, strike and dip measurements, cross section construction, and surface construction for 3D models. Once completed, we utilize the 3D 
map as a base for the kinematic models. In general, we followed a workflow (Fig 8) outlined in Pavlis (2011). 


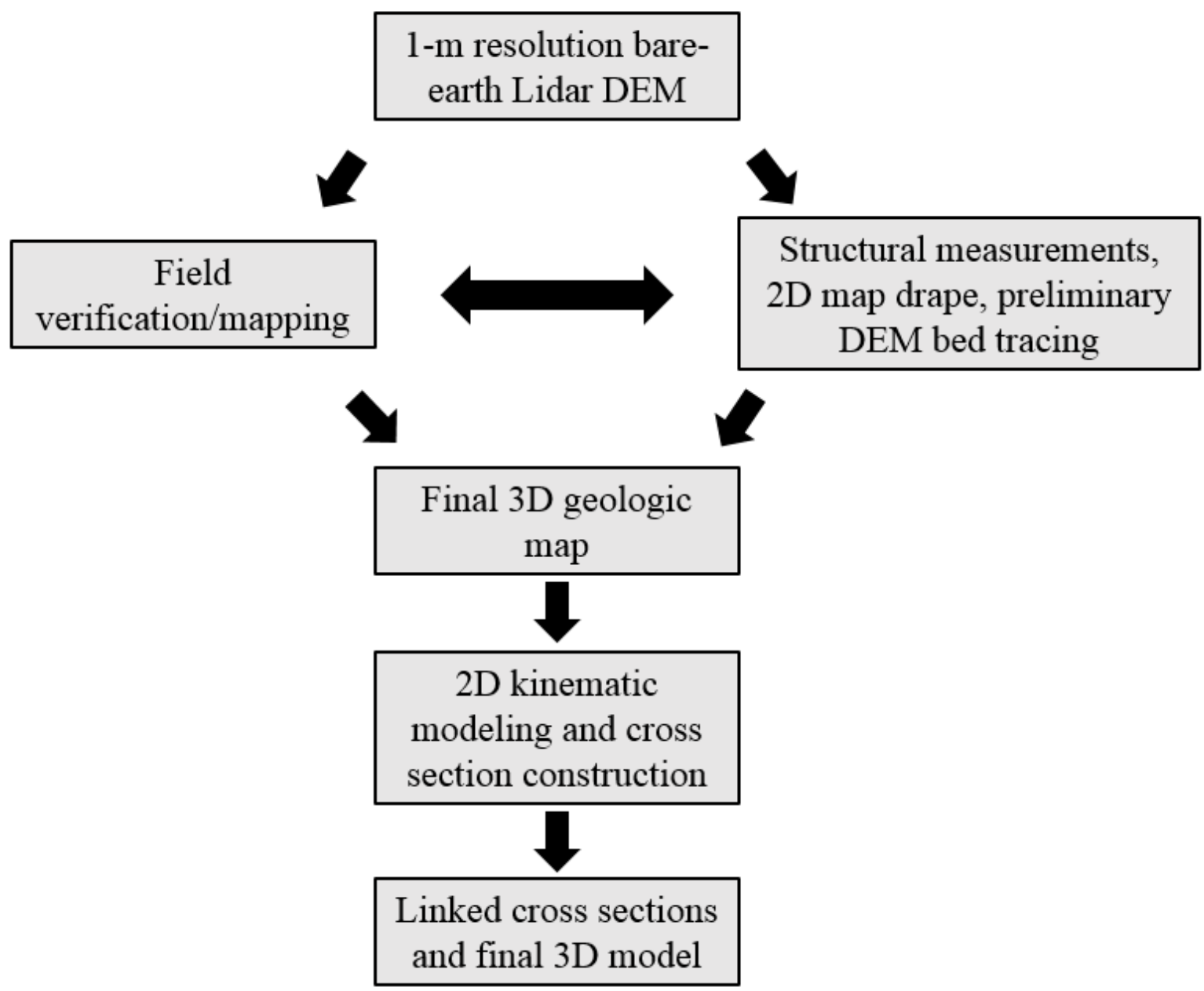

Figure 8: Generalized workflow for the use of Lidar bare-earth DEM's for 3D geological mapping and construction of 3D structural models, modified from Pavlis (2011). 


\section{Lidar derivatives - Geomorphometry}

Figure 7 shows the effectiveness of conducting secondary analysis on the Lidar DEM. In a few short moments, we were able to highlight bedrock bedding planes and outcrop exposures by using the surface geometry utility in MOVE. As the primary goal of this study was to extract the maximum amount of structural information from the Lidar, we also tested using statistical methods in ArcMap. Many Lidar-based studies have utilized quantitative terrain analyses such as DEMbased Geomorphometry for mapping large-scale structural features (Ganas et al., 2005) and landslide analysis (Gritzner et al., 2001). Geomorphometry is the science of topographic quantification (Pike, 2009), and through statistical packages provided by the Geomorphometry and Gradient Metrics Toolbox extension in ArcMap (Evans et al., 2014), several "land surface parameters” can be extracted from the Lidar DEM. The textures derived from the Lidar DEM include Surface Relief Ratio (Pike, 1971), Slope Position or Landform (Berry, 2002), and Surface roughness (Riley et al., 1999; Blaszczynski, 1997). Each of these textures was evaluated on how well they emphasized geological structural features such as joints, folds, and bedding planes. 


\section{Cross Section Generation: 2D Kinematic Modeling}

Using the structural information revealed by fieldwork and Lidar DEM, we tested the existing structural cross sections (Sites, 1971; Gerritsen, 1988) and came up with original interpretations on fold kinematics for the Cave Mountain Anticline and Peacock Cave Anticline through the forward modeling tools provided in MOVE. As most of the Cave Mountain Anticline has been eroded and there is no seismic data at a useful resolution, we utilized the kinematic modeling modules to test different interpretations, to generate the fold shape for our cross sections and to build our intuition on how structures extend into the subsurface. The structures we generated were then evaluated based on how well they fit the 3D map as well as the how they compared to the geometry of the folds revealed in Lidar DEM. After the balanced cross sections were complete we linked the sections in order to generate a 3D visualization of the Cave Mountain Anticline, adjacent folds, and fault geometry of the Cave Mountain thrust along strike and at depth.

The forward modeling modules in MOVE allows for user-control on the placement, initial geometry, and amount movement during fault and fold development. Deformation of strata is then predicted through folding algorithms. The primary fold forward modeling algorithms used include (1) Trishear- developed by Erslev (1991) and Allmendinger (1998), and (2) Detachment foldingbased on the work of Poblet and McClay (1996). Initial model geometry were kept simplistic, assuming a flat-lying package of strata overlying a detachment in the Ordovician Martinsburg formation. 


\section{Trishear}

The Trishear algorithm (Erslev, 1991), is a graphical method which provides an alternative to kinkband models, producing fault-propagation folds with curved geometries and forelimbs with thinned and overturned bedding. In general, the Trishear model deforms beds within a triangular zone of shear, emanating from the tip of a propagating fault. Section area is kept constant, allowing for non-uniform dip and inhomogeneous strain across bedding. Displacement within the trishear zone can be approximated using tie lines (Fig 9A), defined as fault-perpendicular lines which connect the sides of triangular zone (Erslev, 1991). Each tie line creates a polygon with the margins of the trishear zone and adjacent tie lines. Volume comparison of the of the tie line polygons preand post-deformation proves conservation of volume with in the Trishear zone (Erslev, 1991). The shape of the resulting fold is largely controlled through user-defined parameters, including fault angle, propagation-to-slip ratio (P/S), Trishear apex orientation relative to the fault, and Trishear angle. The effects of varying P/S ratios on b the resulting fold geometry are shown in figure 9B.

\section{Heterogenous Trishear}

Erslev (1991) defined two distinct Trishear kinematic models, termed homogenous and heterogenous Trishear (Fig 10). In homogenous Trishear, the Trishear parameters are kept constant throughout deformation, uniformly rotating each tie line, resulting in a single inclined tie line. In constrast, heterogenous Trishear rotates tie line segments in the center of triangular shear zone more than those on the margins (Johnson, 2002). 
A
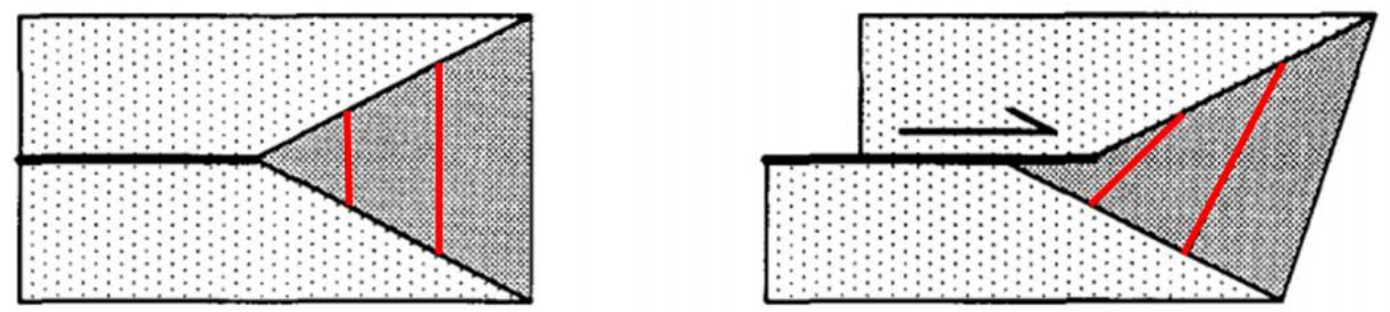

Equal

Volume

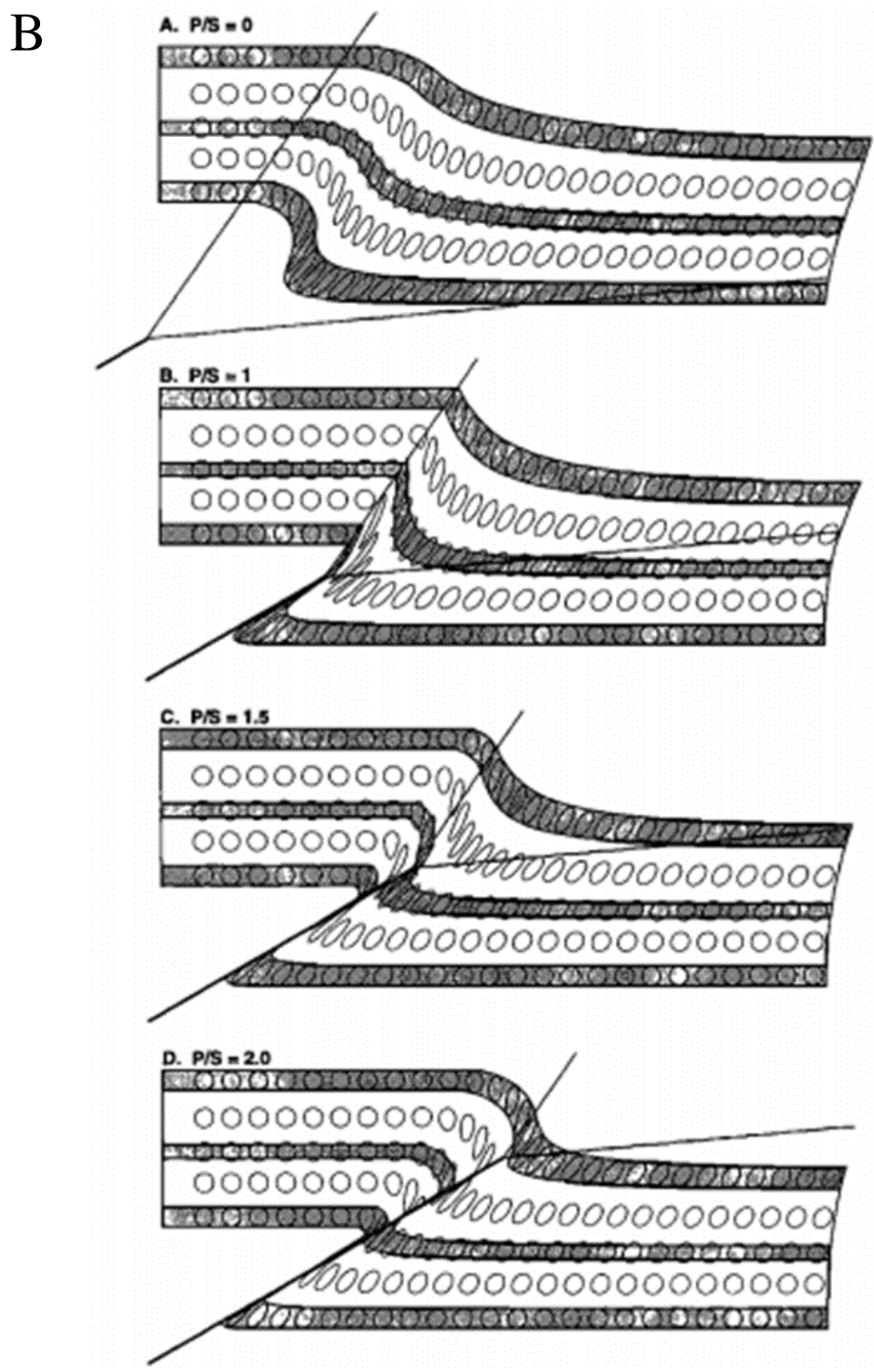

Figure 9: (A) Depiction of tie lines within the Trishear zone (modified from Erlsev, 1991). (B) Diagram of the effects of varying P/S ratio on fold geometry (Allmendinger, 1998). 


\section{Homogenous Trishear}

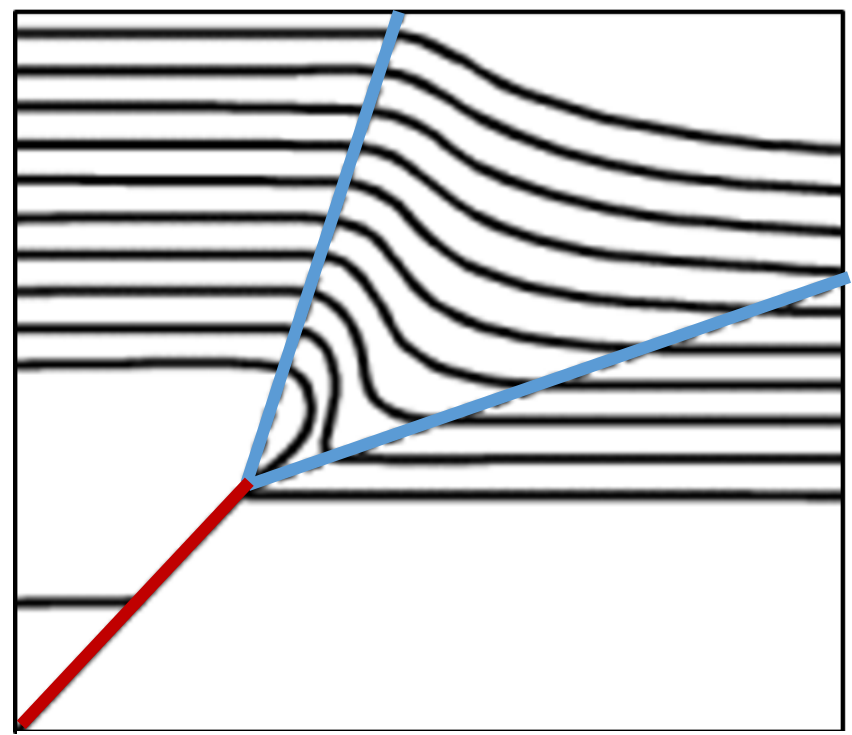

Heterogenous Trishear

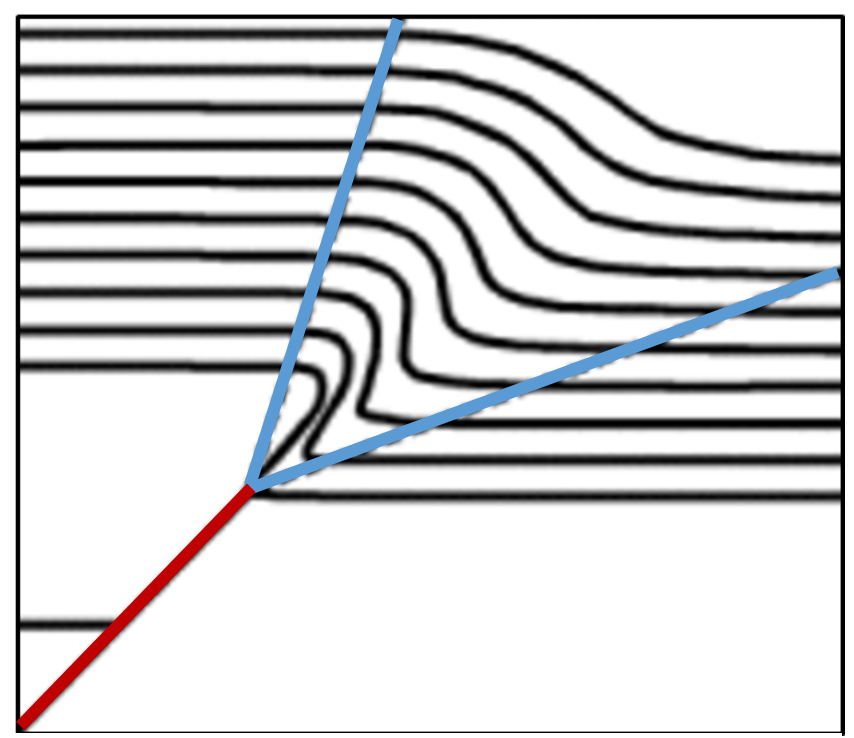

Figure 10: Homogenous versus Heterogeneous Trishear (modified from Johnson, 2002). Changing Trishear parameters with time results in more strongly rotated bedding horizons. 


\section{Detachment Folding}

Deformation west of the Cave Mountain Anticline is dominated by $100-1000 \mathrm{~m}$ wavelength detachment folding. Detachment folds commonly form in sedimentary packages with large differences in mechanical strength above a bedding-parallel detachment (Mitra, 2003; Dahlstrom (1990); Jamison, 1987; Mitra and Namson, 1989; Mitra, 1992; Homza and Wallace, 1995; Poblet and McClay, 1996). Detachment folds (Figure 11) can exhibit a wide variety of geometries, depending on amount of shortening, presence of faults, and multiple detachments (Mitra, 1996). In MOVE, the detachment fold module (Poblet and McCLay, 1996) allows the user to generate folds with different geometries based on whether the fold is modeled with constant limb dip, length, or equal area (limb rotation and lengthening). 


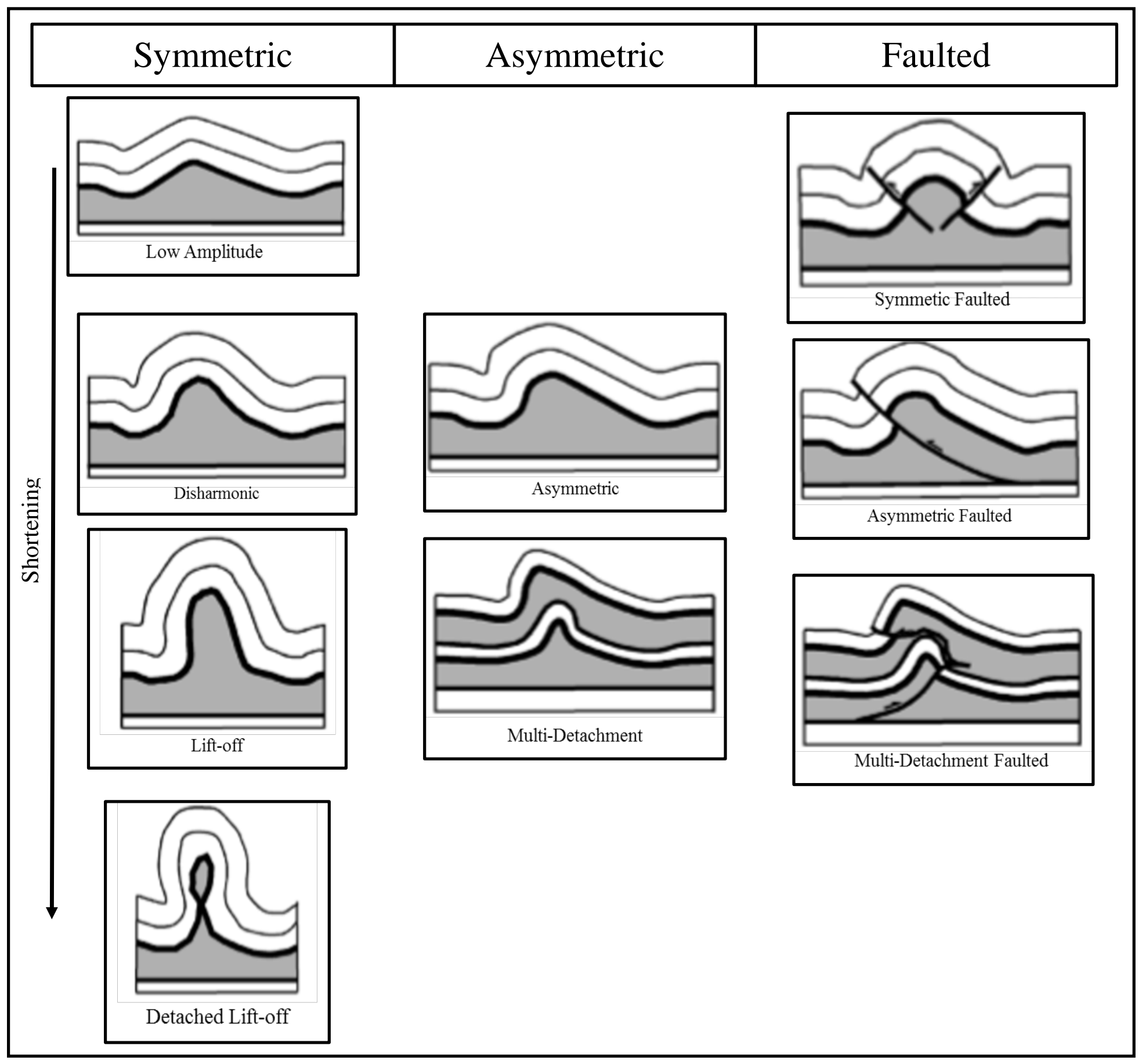

Figure 11: Diagram illustrating the variation in detachment fold geometries based on amount of shortening, symmetry, multiple detachments and presence of faults (Modified from Mitra, 2002). 


\section{RESULTS}

\section{D Geological Mapping with Lidar}

Prior to visiting the field, we began by examining the Lidar DEM as a whole and draping the existing maps (Sites, 1971; Gerritsen, 1988) over the DEM using the control points along the south branch river (Fig 12A, 12B). Our objectives were to compare and contrast the two maps and identify any patterns or trends in the DEM that may be a response to a certain rock unit or lithology.

Closer examination of the draped maps (Fig 12A, 12B) reveals the contacts incorrectly cross over bedding planes in the steep parts of the Cave Mountain anticline. This issue reveals the errors inherently produced when draping any 2D image or map over a DEM in high-relief zones. While this approach can be effective in regions with modest relief, introduction of steeper slopes $\left(>45^{\circ}\right)$ results in spatial errors which cause 3D visualization errors such as pixel smear and distortions (Pavlis, 2017). This effect is also apparent in digital globes such as Google Earth, which use orthocorrected aerial imagery draped over a DEM. In the case of geologic maps, the spatial issues result in incorrect contact positions in steep terrain such as cliffs and ridges. This is a particularly ironic problem as these locations usually provide the most structural information in the field. Furthermore, as many older maps lack geographic coordinates, even more error is introduced in the drape. This effect is visible in the drape of the Sites' (1971) map (Fig 12 B) in which almost all contacts cross bedding planes. 
The next step was to take orientation data on well exposed bedding planes (Fig 12C) in the DEM using Move. These measurements were compared to existing strike/dip data from the two maps. We then conducted fieldwork to determine; (a) which of the two existing maps was more accurate, (b) collect orientation and lithological data, and (c) verify the structural data and structures observed in the Lidar DEM. Fieldwork utilized 3D Lidar images of several points of interest within the field area, as well as enlarged versions of the two geologic maps.

Although the southern half of the canyon has advantages in terms of accessibility, the northern portion has more dramatic and complete exposures of folded strata. Due to large amounts of private land and steep terrain, much of northern half of the area is only accessible via rafting and camping along the South Branch river. Beginning at Big Bend campground, we conducted an overnight rafting trip, collecting structural and lithological data at exposures along the river. 


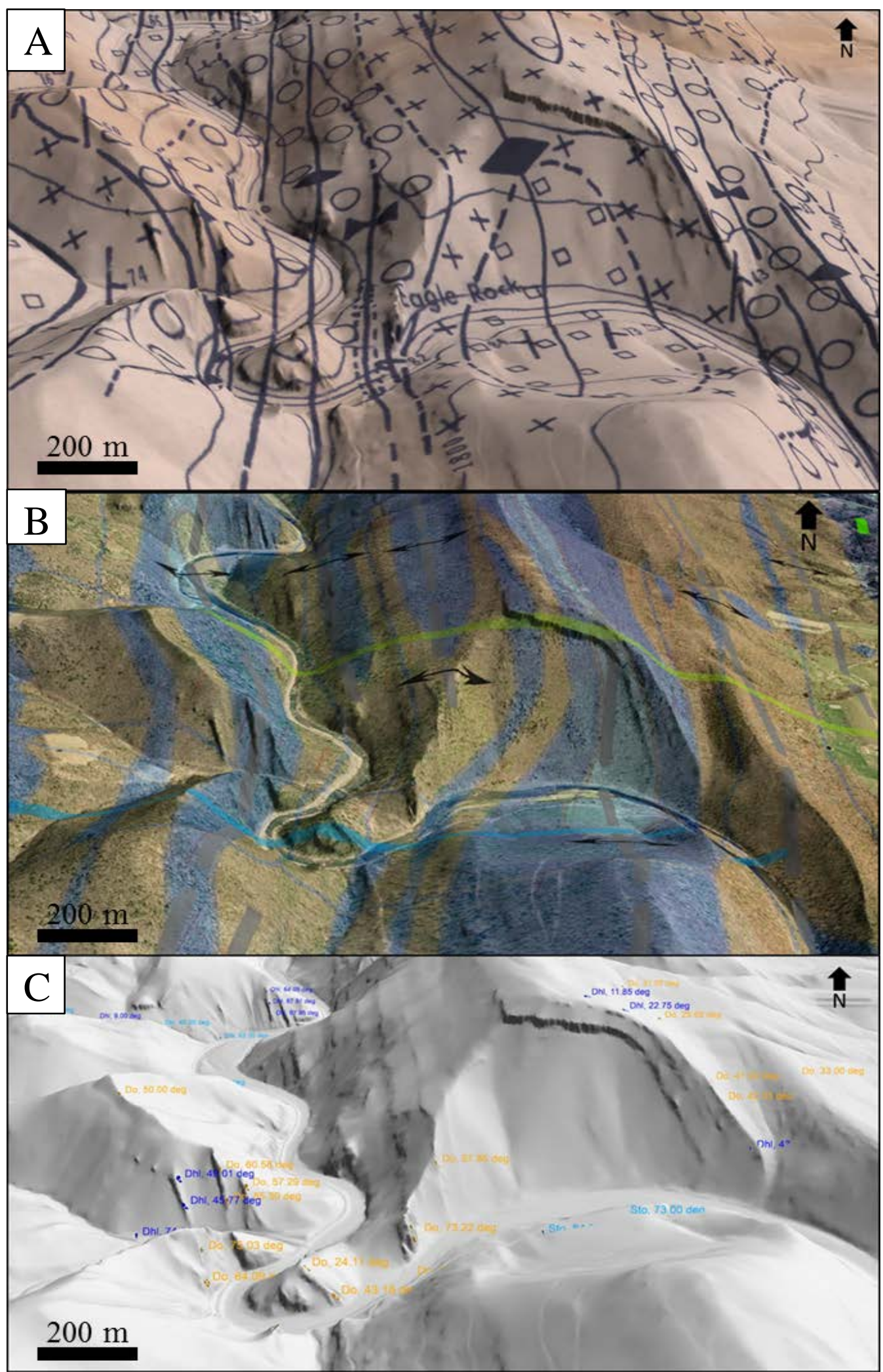

Figure 12: Pre-fieldwork look at the Lidar DEM at Eagle Rock (Fig 2). (A) Initial strike and dip measurements, (B) Gerritsen (1988) map drape, (C) Sites (1971) map drape. 
Following the field reconnaissance check of existing geologic maps by Sites (1971) and Gerritsen (1988) in the field, we decided the map drafted by Gerritsen (1988) was far more accurate. Many of the thrusts mapped by Sites (1971) are non-existent or do not reach the surface as indicated in his cross sections. Additionally, there were multiple large outcrops assigned to the incorrect formation. With this in mind, we decided to use the geologic map drafted by Gerritsen (1988), draped over the Lidar DEM as our template during 3D mapping. After draping the map, we located control points, primarily along the South Branch River, where contacts between mapping units are well exposed and we were confident in the accuracy of the DEM-map drape. Starting at the control point, we drew contact lines directly on the DEM following along prominent bedding planes revealed by the bare-earth DEM. Due to inaccuracies produced from draping a 2D map over a 3D, many contacts had to be adjusted to match the bedding traces in the Lidar. With the ability to alter the sunlight azimuth and angle, we were able to follow thin beds which had not previously been visible. In order to keep the amount of DEM line work to a minimum, we only use solid contact lines, however dashed contacts are also possible with utilities in MOVE. The final 3D geologic map presented was exported in via 3D pdf and as a KMZ file. The 3D pdf which allows for rotation and zoom within adobe acrobat. The KMZ format seems to be the most useful export method as the 3D map can be used as an overlay in Google Earth (Fig 13). This allows for the map to be shared and opened by anyone without the need for the MOVE software, while also allowing for an interactive 3D view of formation contacts, faults, and folds.

As we mapped we also noted that some of the mapping units displayed a characteristic expression in the Lidar DEM. The best example is the Silurian Tonoloway formation (Fig 14), which is composed of primarily thin bedded, grey to black platy limestone. In the upper portion of the formation there are groups of closely spaced, resistant beds which were picked up by the Lidar 
scan and create a distinct pattern in the DEM. This proved useful for identifying the Tonoloway using the Lidar, as well as for verifying the accuracy of the 2D map drape. The other resistant formations in the mapping area include the Silurian Tuscarora formation and the Devonian Oriskany and Helderberg formations. Although these units are well exposed thanks to erosion and differences in mechanical strength, they did not display a characteristic expression in the Lidar to allow us to map them confidently without the map or fieldwork. This limitation shows that despite the usefulness of the Lidar DEM, it not a replacement for good traditional "boots on the ground" mapping and should always be verified for accuracy in the field. 


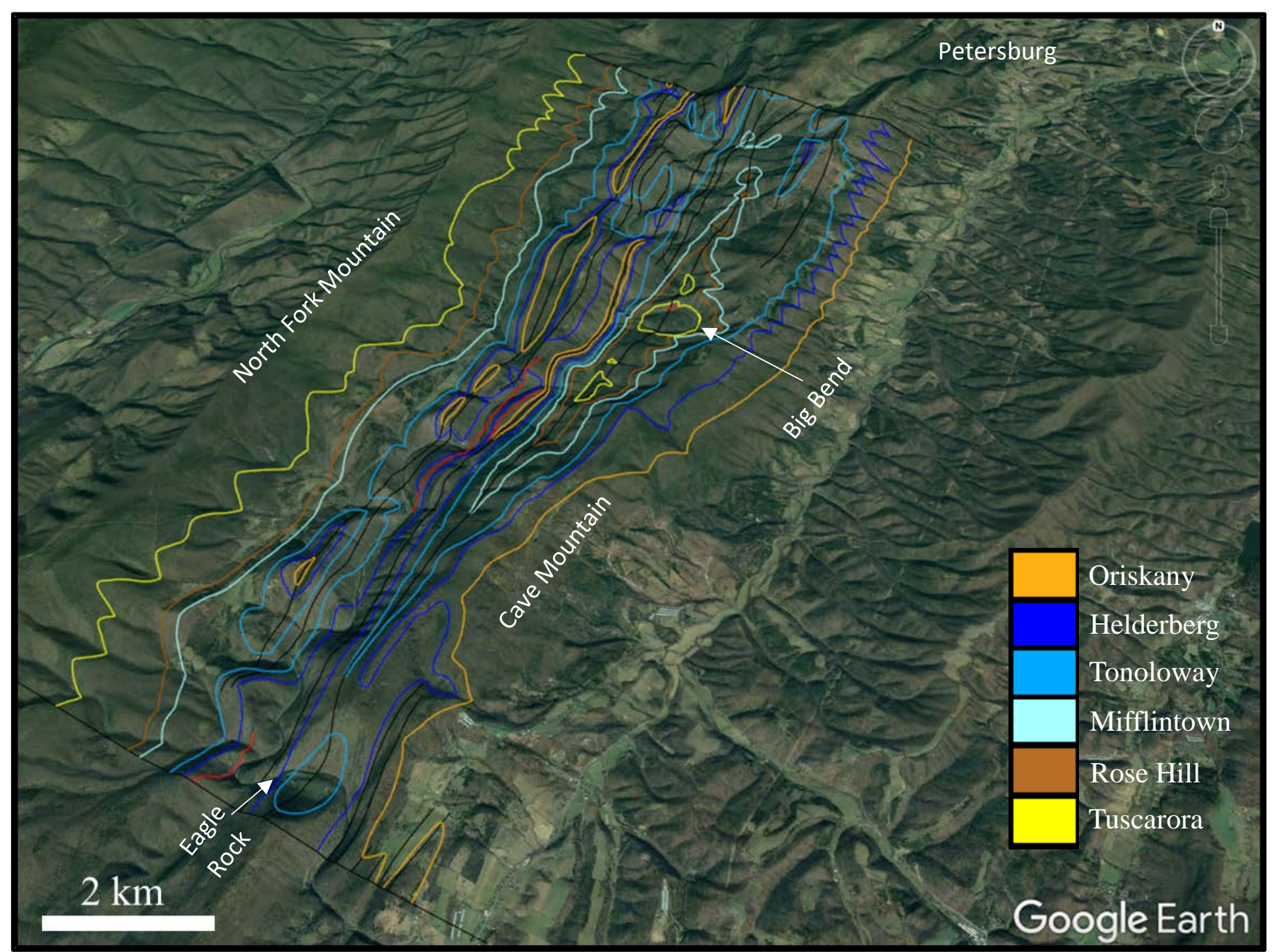

Figure 13: Snapshot of the 3D geologic map exported to Google Earth. Points (A) and (B) mark Tonoloway exposures illustrated in figure 14. 

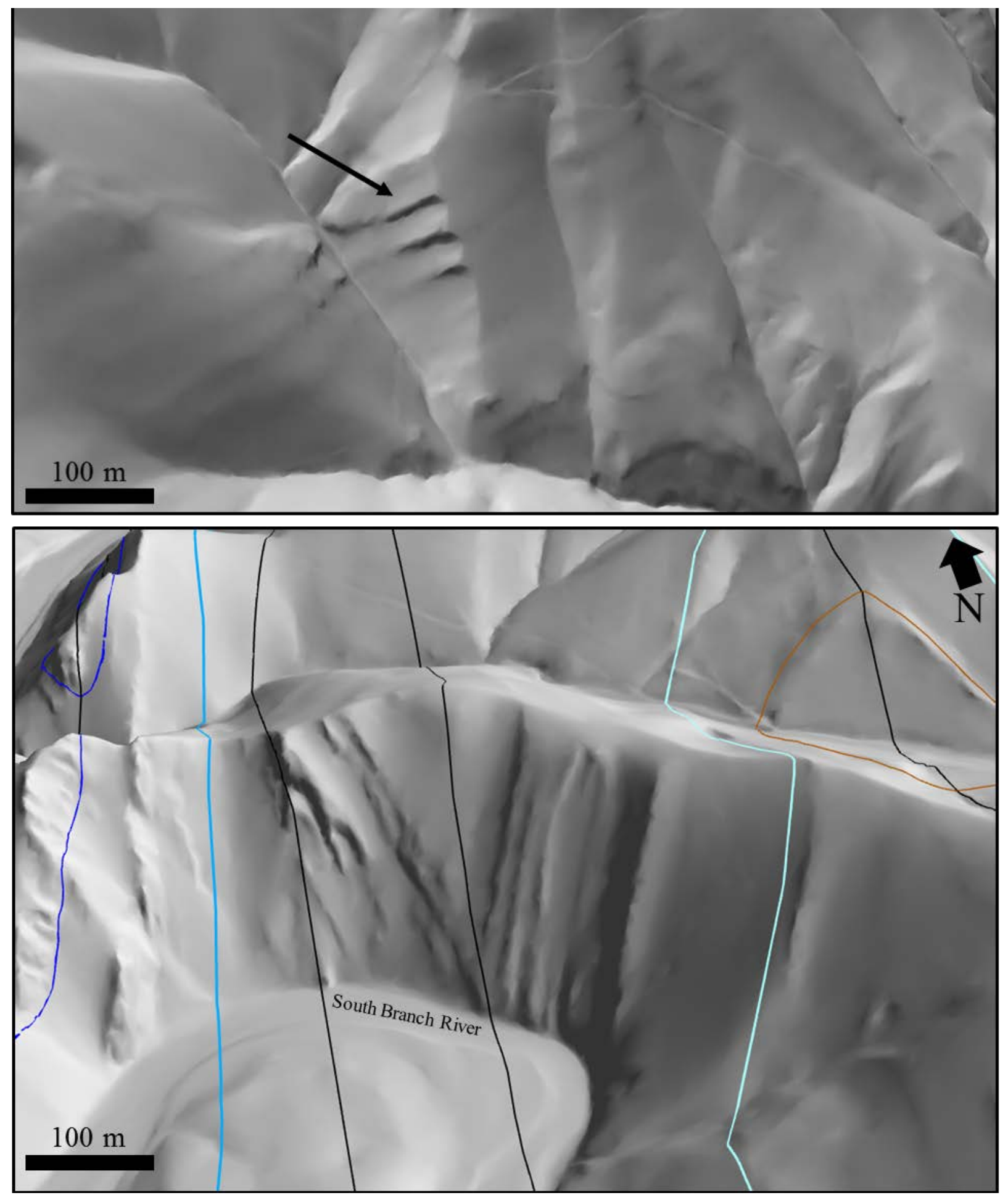

Figure 14: Characteristic expression of the Tonoloway formation in the Lidar DEM. (A) Tonoloway exposure on SE-dipping backlimb of the Cave Mountain Anticline, (B) Folded Tonoloway exposure along the South Branch River. Locations shown in figure 13. 


\section{Results: Geomorphometry}

Figure 15 shows a comparison the primary results of the statistical analysis provided by geomorphometry package in ArcMap. Each land-surface parameter was evaluated based on how well it emphasized structural features picked up by the Lidar scan. The structural features we focused on (Figure 15) were; (A) large saw-tooth features which resemble joints in map-view, (B) a fault propagation fold that was previously hidden by vegetation and/or inaccessible, and (C) bedding planes. From left to right, the land-surface parameter we tested are: shaded relief ratio (Pike, 1971), landform or slope Position (Berry, 2002), and surface roughness (Riley et al., 1999; Blaszczynski, 1997).

The $100 \mathrm{~m}$ long, NE-SW trending saw-tooth features (Fig 15A) are located on SE-dipping cliffs made up of Tuscarora sandstone, and were only noted once we generated the landform terrain surface texture. Although our initial thoughts were that these were joints, a visit to the location in the field revealed that the linear features actually represent very slight topographic depressions not visible at the surface. These linear depressions are connected by rounded, north-south trending elevated "mounds" of loose outcrop and brush. This indicates that although the Landform surface texture may have helped us identify the feature, it exaggerated the amount of relief actually present. After much discussion, we believe these features may represent the margins of a thin "slab-slide”, a common landslide feature found in the Central Appalachian Valley and Ridge province.

Just north of Big Bend near the center of the study area there is a fault-propagation fold created by a small back thrust (Fig 15B). Although this fold has been identified by previous authors, it is inaccessible on foot and its geometry was not clearly visible until we generated the surface roughness and landform terrain surface textures. surface roughness, a terrain ruggedness index which quantifies topography heterogeneity (Riley et al., 1992), allowed us to quickly notice the 
fold by emphasizing the resistant Tuscarora outcrops from the surrounding ridge-side. We were then able to further distinguish specific bedding orientations and fold geometry through the landform surface texture, which did an excellent job of delineating bedding planes at a wellexposed outcrop.

Lastly, we tested which land surface texture was most useful for identifying bedding plane traces (Fig 15C), in order to help us determine structural trends at a larger scale in areas with less exposure. Although bedding was visible in all three land surface textures, surface relief ratio (left) and surface roughness (right) proved to be the most useful in visualizing bedding planes at a broader scale.

Although these land surface textures each have their own individual strengths in emphasizing geological features, it is apparent from the results of the geomorphometry analysis that they should be used in combination. Use of any of these surface textures without comparison with another can result in error of interpretation, as was the case with the linear features in row (A). Overall, the geomorphometry analysis proved to be helpful in delineating bedrock features and can be done relatively quickly through the ArcGIS Geomorphometry and Gradient metric toolbox. 


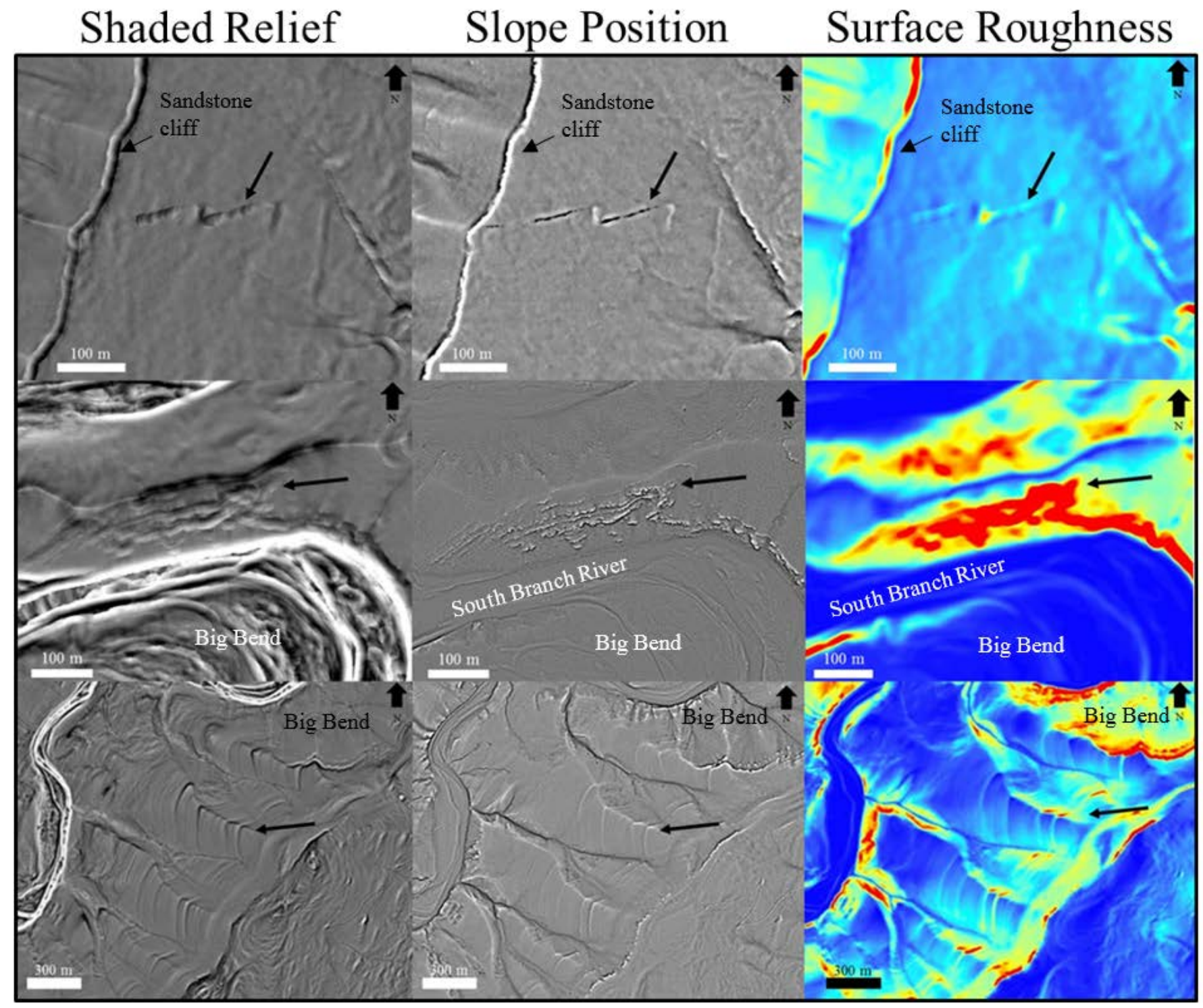

Figure 15: Comparison of the geomorphometry analysis results, including (left to right) shaded relief, slope position (landform), and surface roughness. Row (a): $100 \mathrm{~m}$ long joints on North Fork Mountain within the Tuscarora formation. Row (b): SE-verging meso-scale fold within the Tuscarora Formation at Big Bend. Row (c): bedding planes on the anti-dip slope of the CMA near Big Bend. 


\section{Results: Interpretations from Kinematic Modeling}

\section{Cave Mountain Anticline}

We began by comparing the interpretation by Gerritsen (1988) to the fold geometry mapped at Big Bend, where the core of the Cave Mountain anticline is exposed. Gerritsen (1988), interpreted the Cave Mountain anticline as a box fold above a detachment approximately $90 \mathrm{~m}$ below the top of the Martinsburg formation. Early on, we noted that the anticline generated by the kinematic model using Gerritsen's detachment horizon would produce a fold which is too small and did not fit the geologic map or dip distribution observed in the DEM, indicating the detachment is deeper than previously interpreted (Fig 16). Additionally, reproducing the overturned, and often thinned forelimb also proved to be difficult using the detachment fold model. The detachment folds we were able to model with overturned forelimbs displayed homogenous forelimb dip, a feature not observed in field. As a result, we decided to test a thrust-fault interpretation utilizing the Trishear fault-propagation folding algorithm in MOVE.

Multiple iterations were performed using different Trishear parameters. All models used a $30^{\circ}$ thrust propagating from a detachment in the Martinsburg formation. Although some of the models came close, none fit the dip distribution and forelimb thinning seen in the field and Lidar DEM. For this reason, we decided that Trishear deformation was the appropriate module, however some of the Trishear parameters must change over time.

In heterogeneous Trishear deformation (Allmendinger, 1998), one or more of the parameters (P/S ratio, apex angle, angle offset) are altered during the forward modeling process (table 1). Although most studies use constant Trishear parameters, geologists have learned that the Trishear parameters often change during deformation (Pei et al., 2017), especially in packages of strata with large 
contrasts in mechanical properties. In general, high competency rocks usually present higher P/S ratios and narrower apical angle than rocks with low competency (e.g., Allmendinger, 1998; Hardy and Ford, 1997; Pei et al., 2014). With the exception of the Tuscarora sandstones, the stratigraphy of the smoke holes progressively increases in mechanical strength moving upwards. With this in mind, we decided to decrease the Trishear angle throughout the forward modeling process until the final geometry displayed the bedding orientations and thickness changes noted in the field and Lidar DEM.

The variable Trishear model was composed of 3 different stages, each with 4 deformation "steps" of $150 \mathrm{~m}$ of displacement. A P/S ratio of 1.25 and angle offset of 0.6 were kept constant through all stages. The Trishear apex angle however, was initially set to $65^{\circ}$ and then progressively decreased by $5^{\circ}$ in each stage. We experimented with increasing the P/S ratio but found that it resulted in the exposure of the Cave Mountain Thrust at the surface, as well as fold geometries which did not fit the bedding orientations observed in the Lidar.

Heterogeneous Trishear with a decreasing apical angle using a blind thrust stemming from a detachment in the Martinsburg formation successfully reproduced the Cave Mountain Anticline at Big Bend. Forelimb thinning resulting from the Trishear algorithm during fault propagation is able to replicate the thinned units observed to the west of Big Bend. Furthermore, the dip distribution of the final forward model is a good match with the strike and dip measurements taken from the Lidar and field measurements.

As noted by previous workers (Sites, 1971; Gerritsen, 1988), the geometry of the Cave Mountain anticline changes as it plunges to the North and South from its culmination at Big Bend. To the south, the backlimb of the fold steepens, while overall fold size decreases. To the north, the fold splits in to two separate folds, and shows a forelimb with a kinked fold. Although our Cave 
Mountain anticline model was a good fit at Big Bend, different Trishear and fault parameters were required as we modeled the Cave Mountain anticline along strike. 


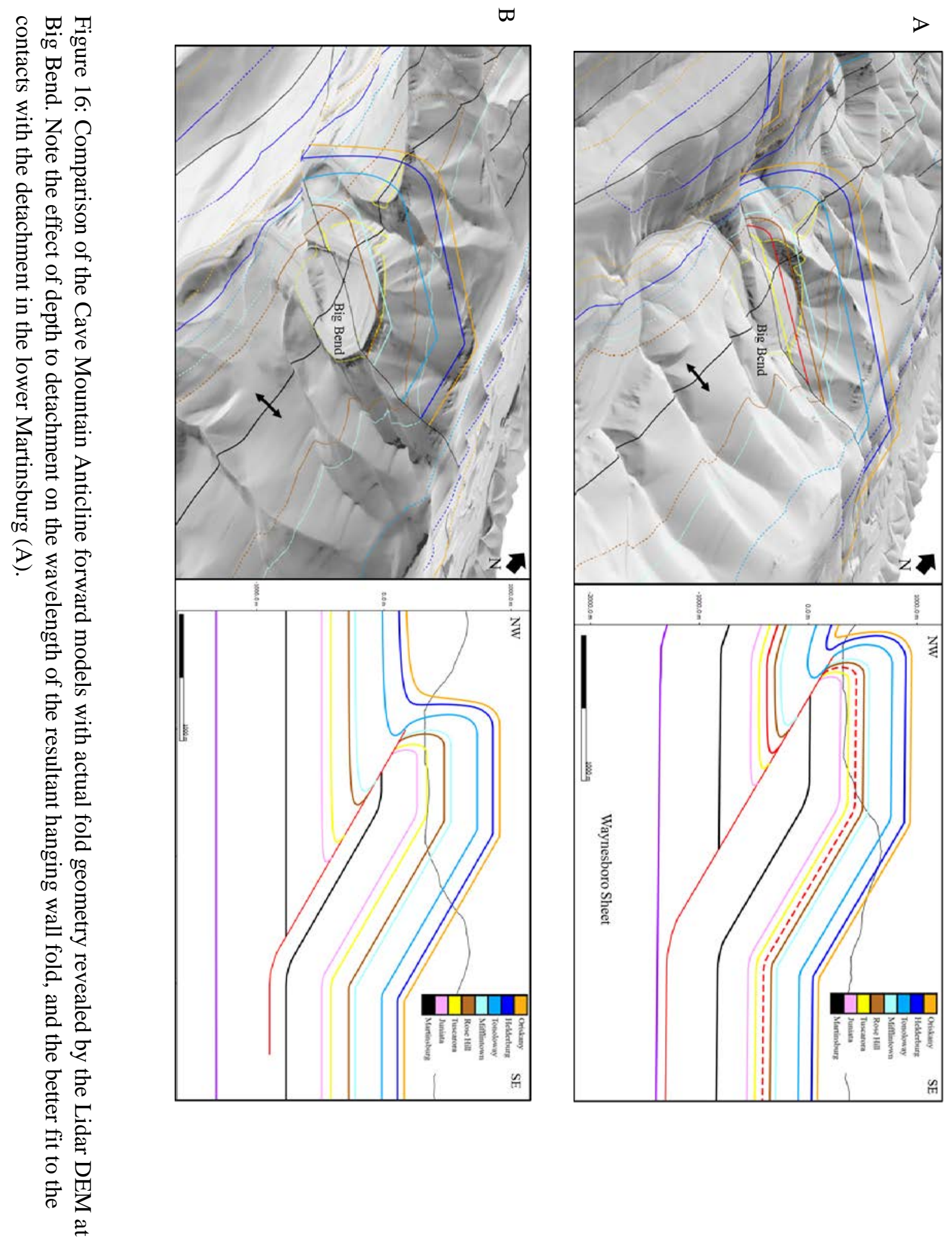


Cave Mountain Anticline: Eagle Rock

Another great exposure of the Cave Mountain anticline is at Eagle Rock near the southern end of the canyon (Fig 17). Here, the anticline has been dissected perpendicular to strike, allowing the Lidar DEM to provide strong control on the size and shape of the fold. Furthermore, Eagle Rock allows for direct measurement of strike and dip of the overturned forelimb. In comparison to Big Bend, several differences in fold geometry are evident, including the size of the anticline as well

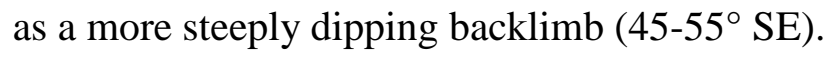

Through kinematic forward modeling we found that we could not reproduce the southern portion of the Cave Mountain Anticline using the same depth to detachment and Trishear parameters as in the Big Bend cross sections. A detachment in the Martinsburg formation (1100-1200 m) for the Cave Mountain thrust results in a hanging wall anticline which is much broader than Cave Mountain Anticline at the southern end of the canyon (Fig 17). To account for the observed changes in geometry we first increased the dip of the thrust to $45^{\circ}$ to produce a steeper backlimb. We then decreased the depth to detachment until the resulting anticline was the same wavelength as observed in the Lidar DEM. Dip distribution here is much more uniform as only the top units in the section are exposed (Oriskany, Helderberg, and Tonoloway), so heterogeneous Trishear was not required to model the fold. As the detachment depth is shallower, less displacement was required, with approximately $1000 \mathrm{~m}$ of displacement estimated by the kinematic models. Therefore, a lateral ramp is necessary between Eagle Rock and Big Bend (Fig 19). 


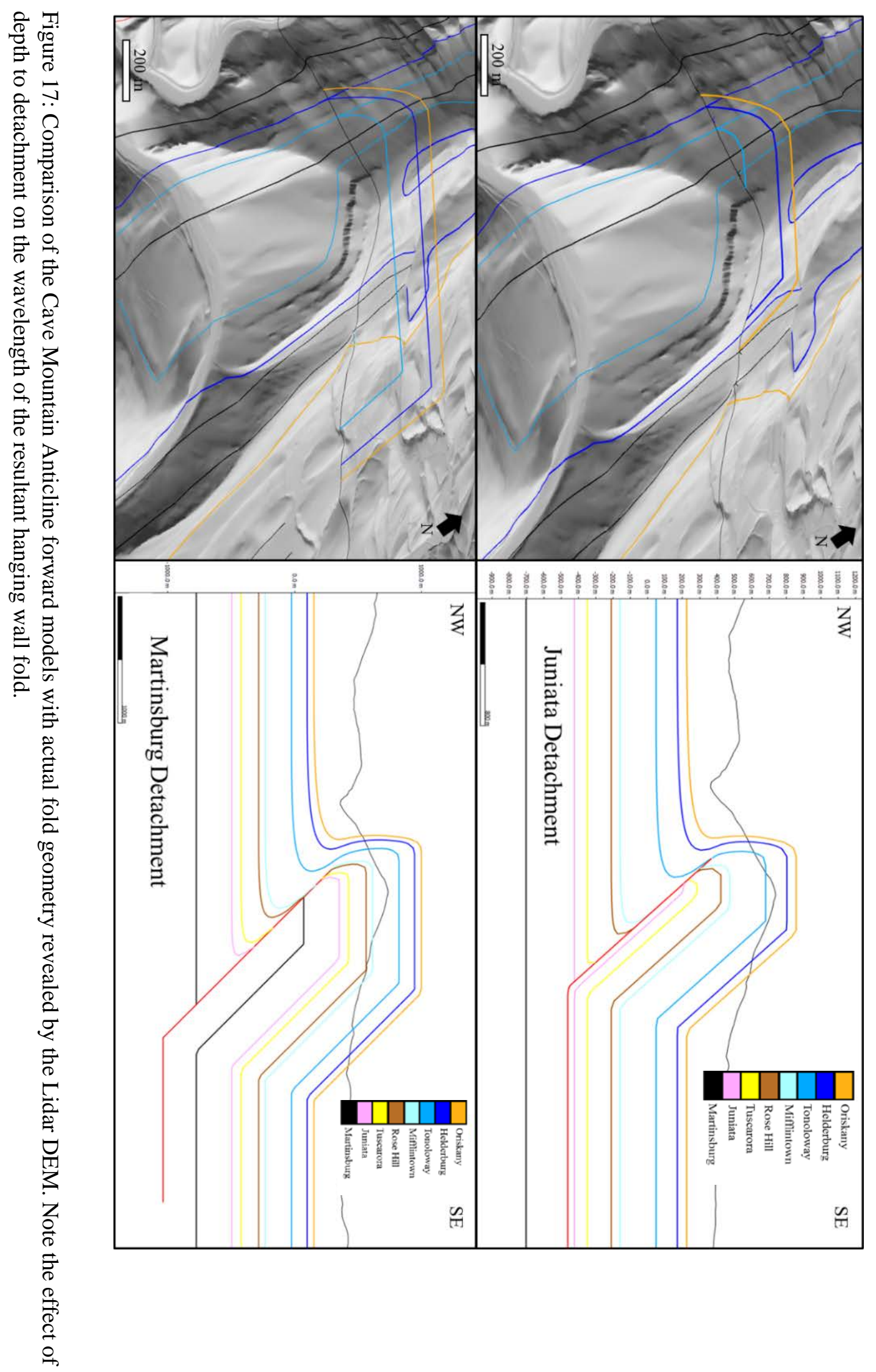




\section{Cave Mountain Anticline: North}

To the North, the structural complexity of the anticline increases as it splits in to two separate folds. Additionally, there are low wavelength (100-300 m), symmetrical folds with kinked geometry located directly along strike from the forelimb to the south (Fig 18). Due to complexity limitations of the Trishear algorithm, we chose to use the traditional kink-band fault-propagation algorithm for this section of the Cave Mountain Anticline.

We modeled the splitting of the Cave Mountain Anticline by interpreting that the main thrust branches in to two separate thrusts moving northward, resulting in an imbricate thrust geometry (Fig 22). According to the kinematic modeling, depth to detachment is also decreasing to the north, with a detachment in the upper Martinsburg (600 m). Displacement on the fault is redistributed between the two thrusts, with an estimated $500 \mathrm{~m}$ of displacement on the eastern thrust and $580 \mathrm{~m}$ on the western (main) branch. According to the kinematic model, depth to detachment here is also shallower (Upper Martinsburg), requiring another lateral ramp extending north from Big Bend (Fig 19).

The forelimb folds are symmetrical with kinked hinges and wavelengths on the order of 100-300 m. Structurally, they are located directly along strike from the forelimb exposed to the south at Big Bend. In order to generate the Cave Mountain anticline with a kinked forelimb fold, we found that a pre-existing detachment fold above a shallow detachment would need to be present above the propagating Cave Mountain Thrust block. The modeling required the initial fold to have box geometry, broader wavelength and lower amplitude, before being subsequently tightened and amplified during the emplacement of the Cave Mountain Anticline. Models of the pre-existing detachment fold estimate $200 \mathrm{~m}$ of displacement. The result (figure 16) is fault propagation fold with a kinked forelimb which matches the fold geometry revealed in the Lidar DEM. 


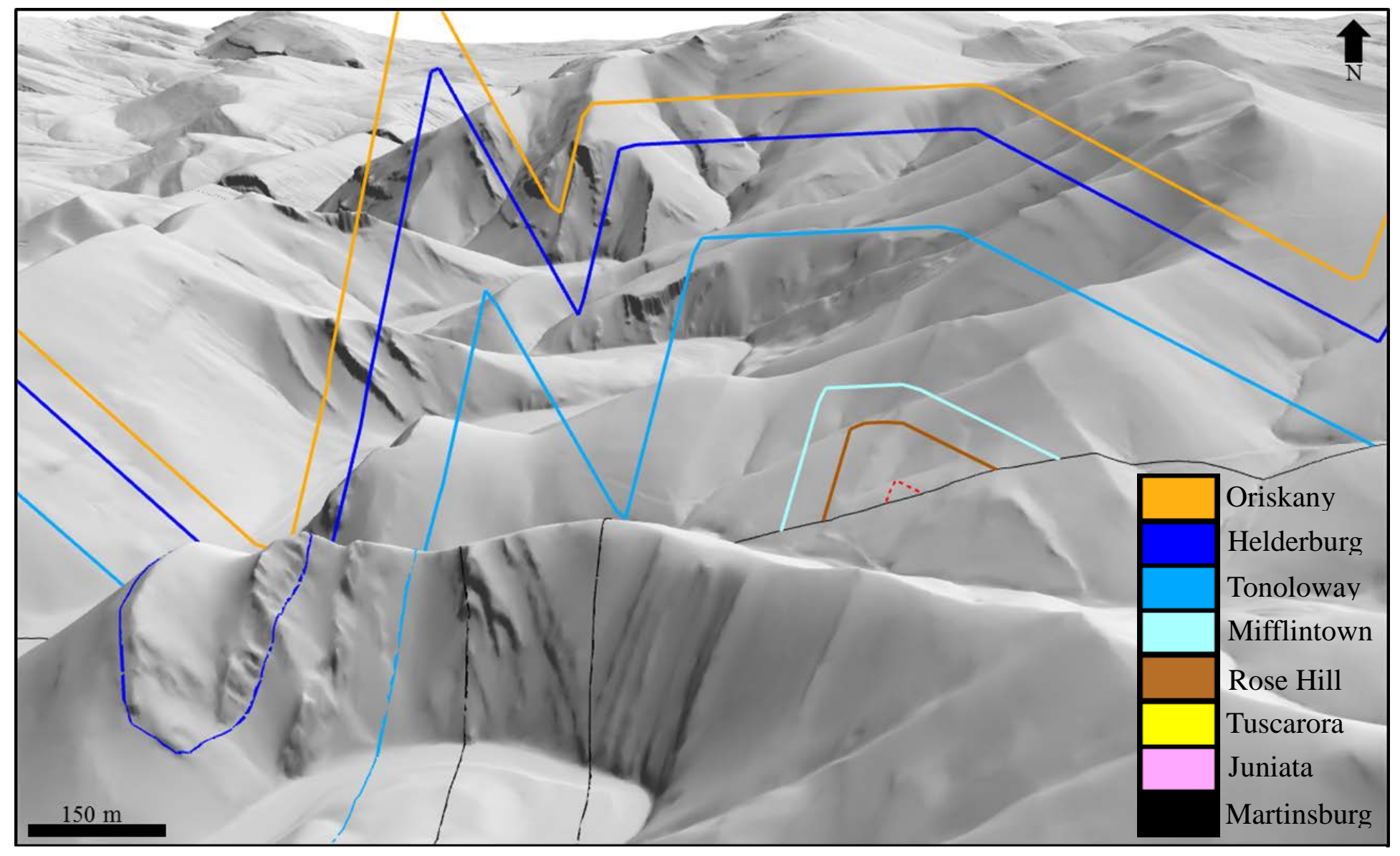

Figure 18: Lidar comparison with the kinematic model of a propagation fold with a kinked forelimb. 


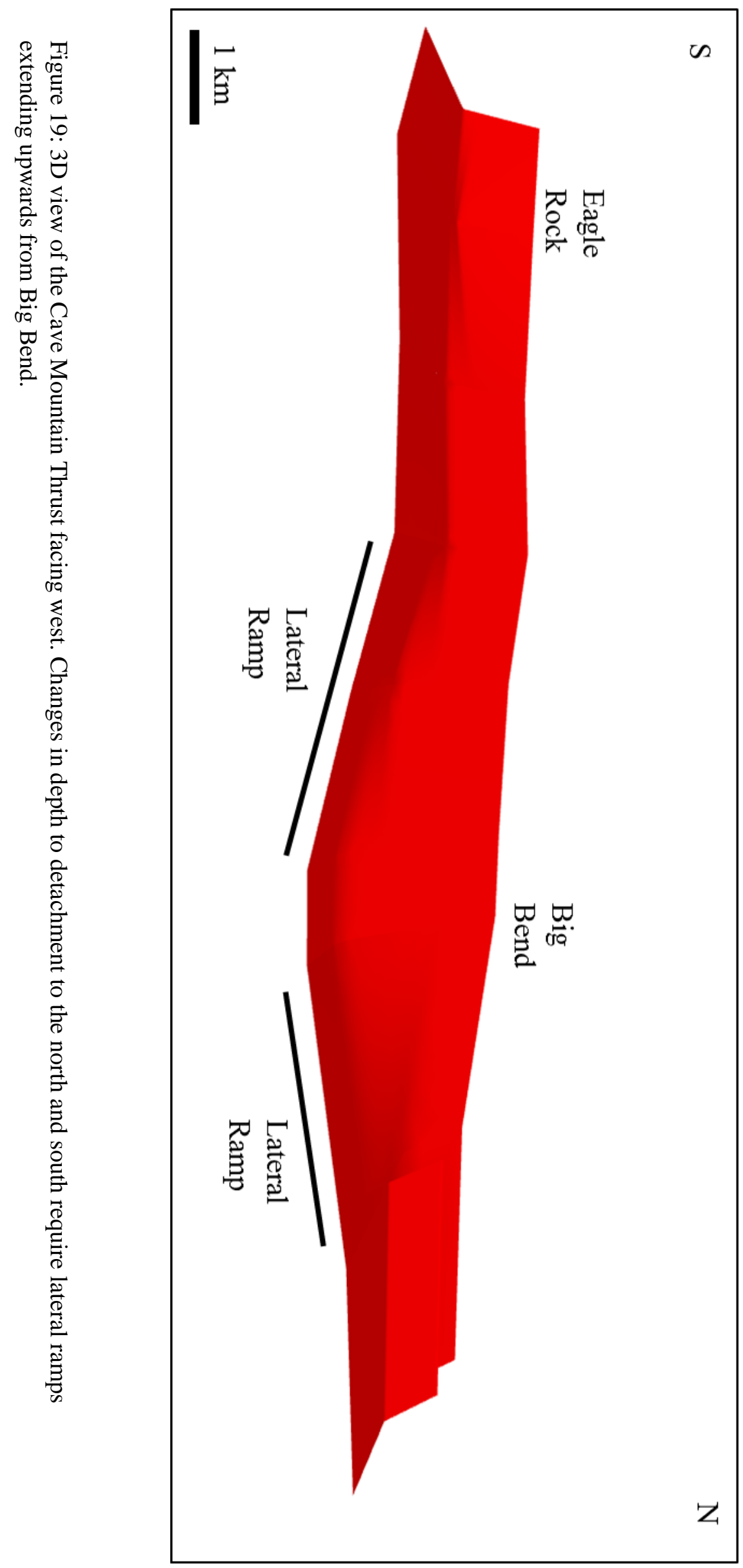




\section{Detachment folding}

The area surrounding the Cave Mountain anticline is also deformed by much shorter wavelength folds. Based on the geometries revealed by the Lidar DEM we determined that the folds were 100$1000 \mathrm{~m}$ wavelength detachment folds. Anticlines tend to be symmetric and display lift-off to box shaped geometries (PCA; Fig 17), while synclines are tight and symmetrical to asymmetrical. Forward modeling of cover sequence lift-off folds using a detachment horizon in the Martinsburg formation could not reproduce the folds observed in field and the Lidar DEM. A deep detachment in the Martinsburg as interpreted by Gerritsen (1988), produces folds with much broader wavelengths or requires a very large “ductile thickness" value $(>700 \mathrm{~m})$, defined in MOVE as the thickness of the zone across which deformation is accommodated by fault-parallel shear. Based on the size distribution and geometry of the detachment folds revealed in the Lidar DEM, we determined that the high ductile thickness value was unreasonable, indicating that multiple shallower detachment horizons were required.

For the larger detachment folds such as the Peacock Cave Anticline ( $>500 \mathrm{~m}$ wavelength) we select the shales of the Rose Hill Formation as the new detachment horizon. With the exception of the Cacapon Sandstone near the base, this unit contains over $100 \mathrm{~m}$ of shale overlain by several more mechanically weak units, including the shales of the Mifflintown Group and Wills Creek Formation. Furthermore, regional seismic surveys describe this part of the section as mechanically weak relative to the bounding formations (Wilson and Shumaker, 1992). Previous work also estimates that existing thrusts in the area are thought to ramp out of the shale-dominated units of the Rose Hill, Wills Creek or Big Mountain Shales (Gerritsen, 1988). 


\section{Deformational Sequence}

Based on the results of the kinematic forward models, we proposed a 2-phase deformational sequence: (1) $100 \mathrm{~m}$ to $500 \mathrm{~m}$ wavelength detachment folding and localized 50 to $150 \mathrm{~m}$ displacement thrust faulting occurred above multiple layer-parallel detachments, with the main detachment horizon located in the shales of the Rose Hill Formation. (2) Initial folding was later tightened and amplified during the emplacement of the Cave Mountain thrust block. In the northern portion of the field area, the developing Cave Mountain fault-propagation fold intersected with a detachment fold that had developed either before or coevally with the Cave Mountain thrust, resulting in a kinked forelimb. To the north, the main thrust plane branched in two, resulting in the apparent splitting of the Cave Mountain anticline at the surface and creating an imbricated thrust fault geometry at depth. 


\section{CROSS SECTIONS}

D-D’ (Big Bend)

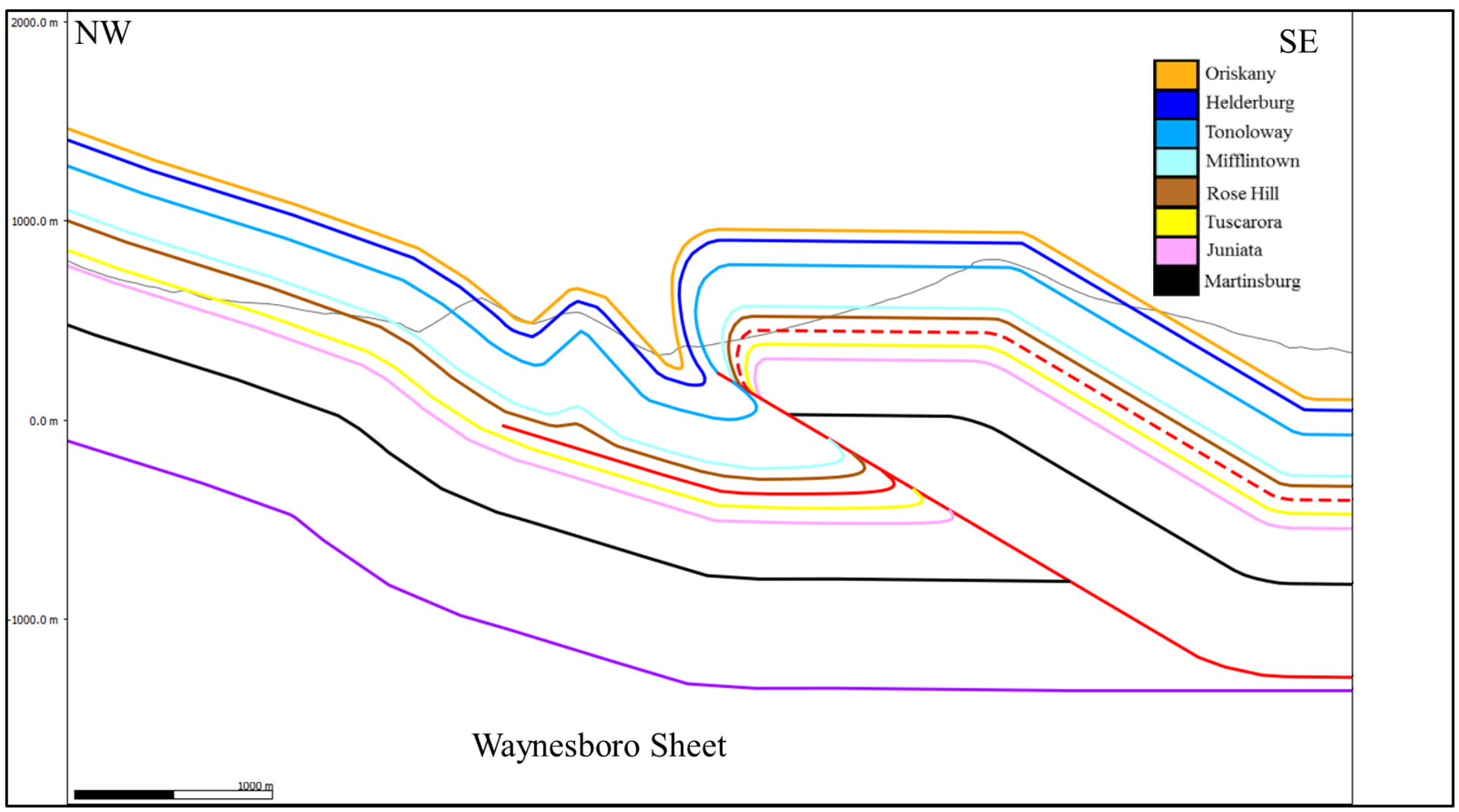

Figure 20: Kinematic forward modelled cross section through the core of the Cave Mountain Anticline at Big Bend. A pre-existing detachment horizon is entrained in the hanging wall anticline of the Cave Mountain thrust, illustrating the out of sequence deformation interpretation. 
I-I’ (Eagle Rock)

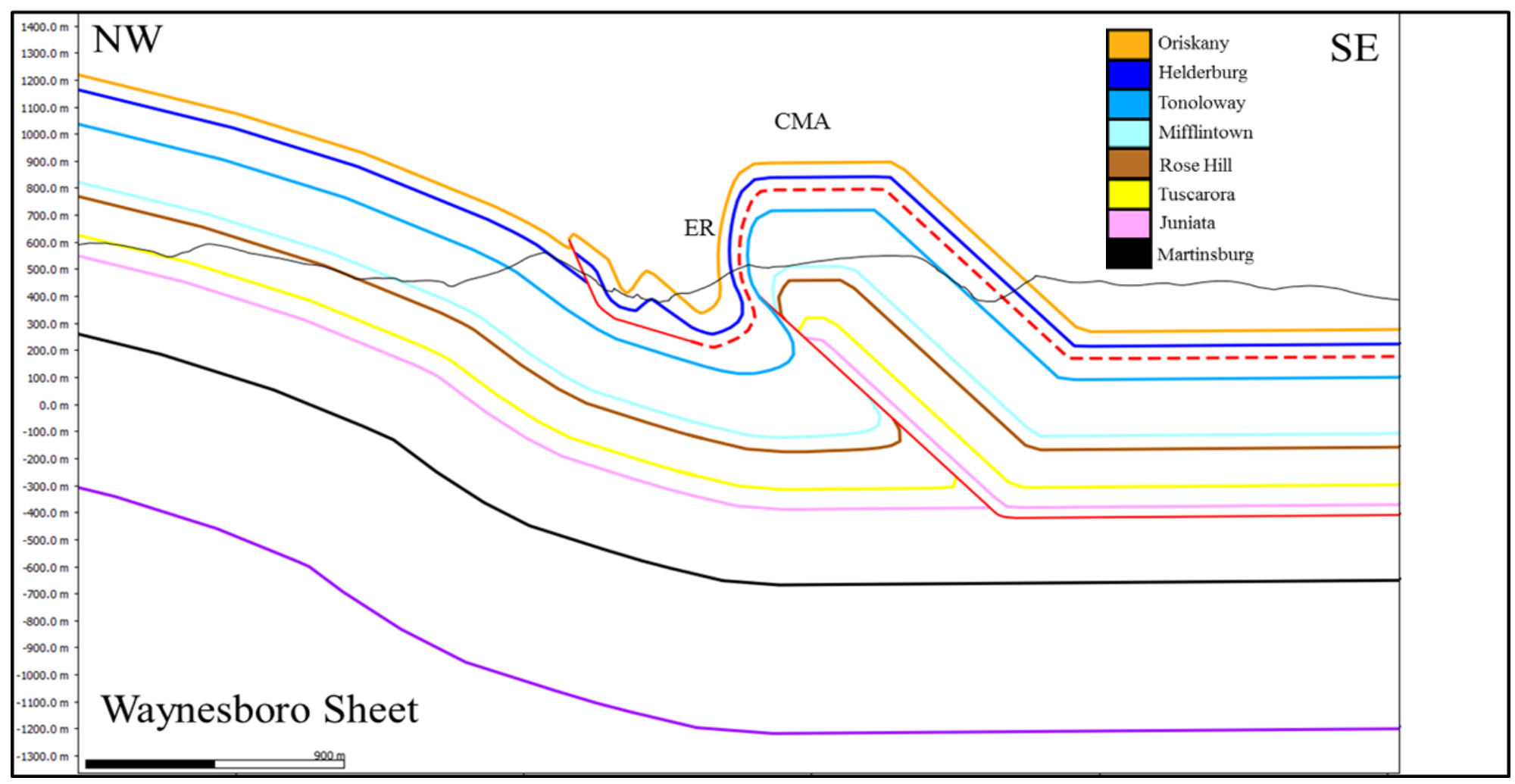

Figure 21: Cross section through the southern end of the study area, illustrating the shallowing depth to detachment of the Cave Mountain Thrust. There are also pre-existing, low displacement forethrusting structures above a shallow detachment in the Tonoloway Fm. (ER: Eagle Rock; CMA: Cave Mountain Anticline. 


\section{B-B’ (North)}

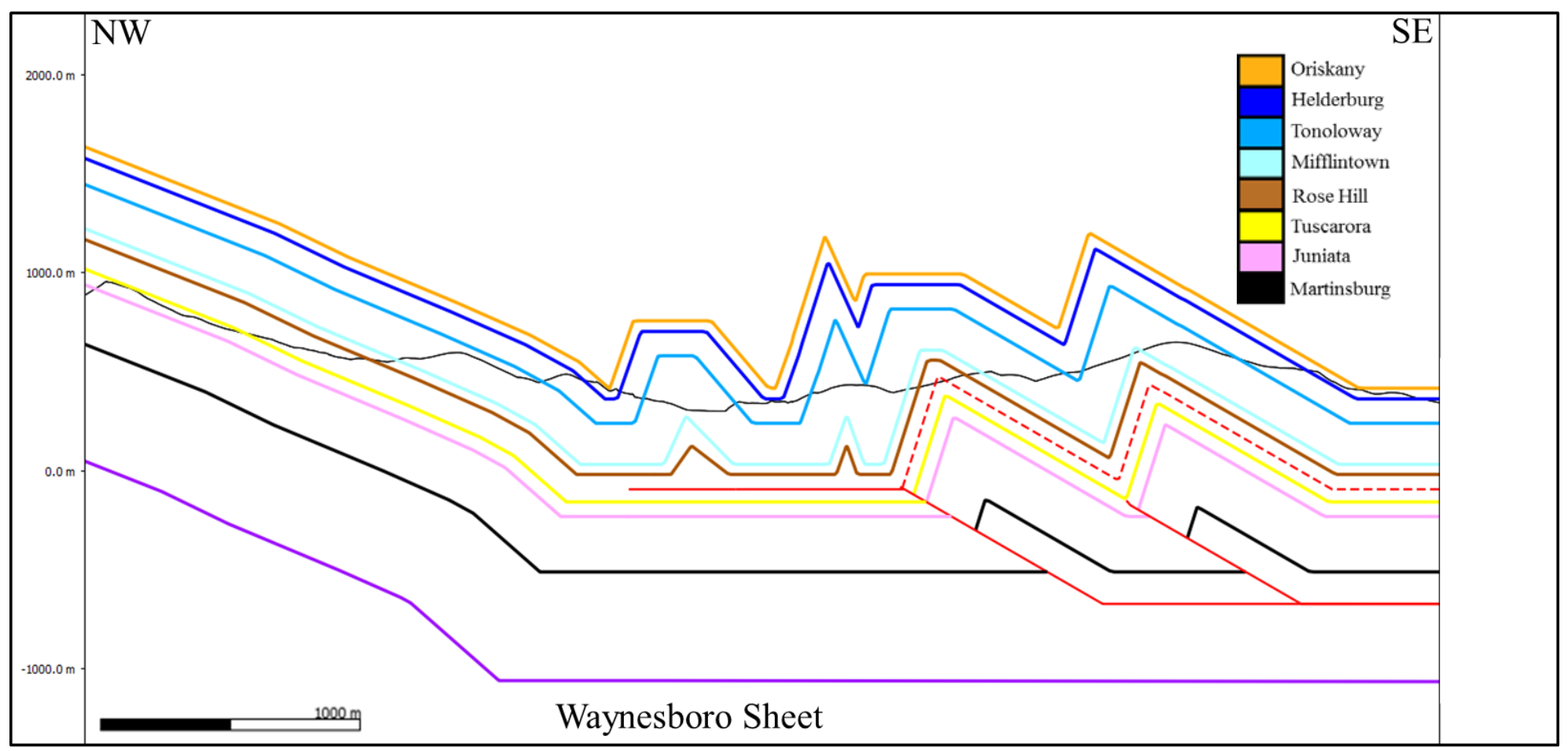

Figure 22: Cross section through the northern part of the study area, showing imbricated thrust geometry and kinked forelimb of the Cave Mountain Anticline (PCA- Peacock Cave Anticline; CMA- Cave Mountain Anticline). 


\section{FINAL 3D MODEL}

Thanks to interpretations from the kinematic models and several changes along strike, it is clear that a 3D model would be a useful tool to visualize the 3D geometry of the Cave Mountain thrust and related fold. The 3D model was generated by linking formation and thrust fault horizons across adjacent cross sections. To maintain a simple, clear image of the fold, we connected the tops of the Oriskany, Tonoloway, and Tuscarora Formations, along with Cave Mountain Thrust. The 3D model can then be exported either as interactive 3D pdf, MOVE file, or several other file types (Fig 23). 
A

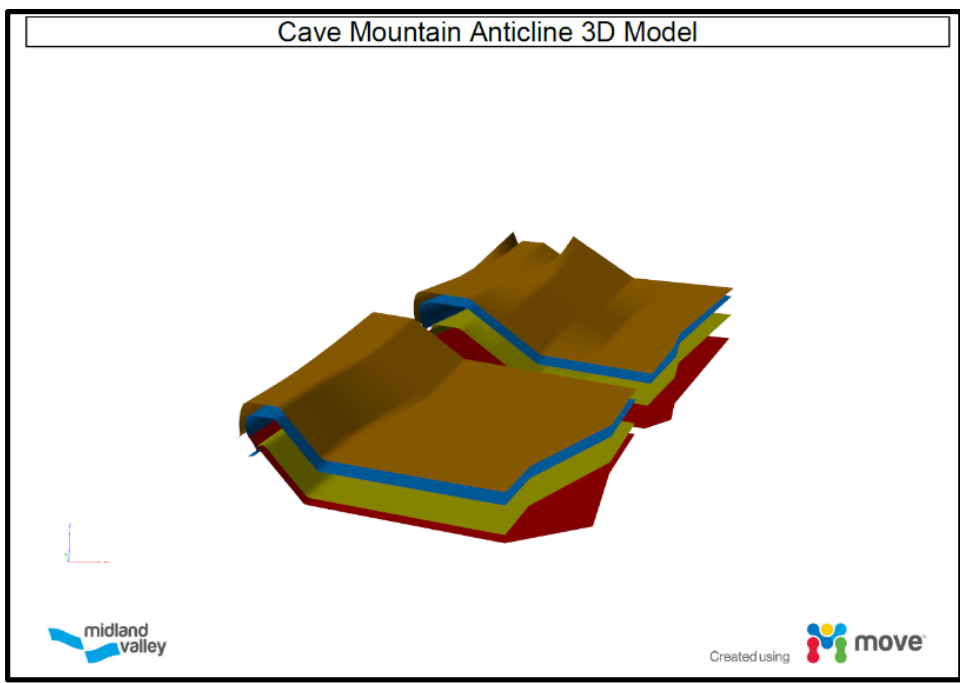

B

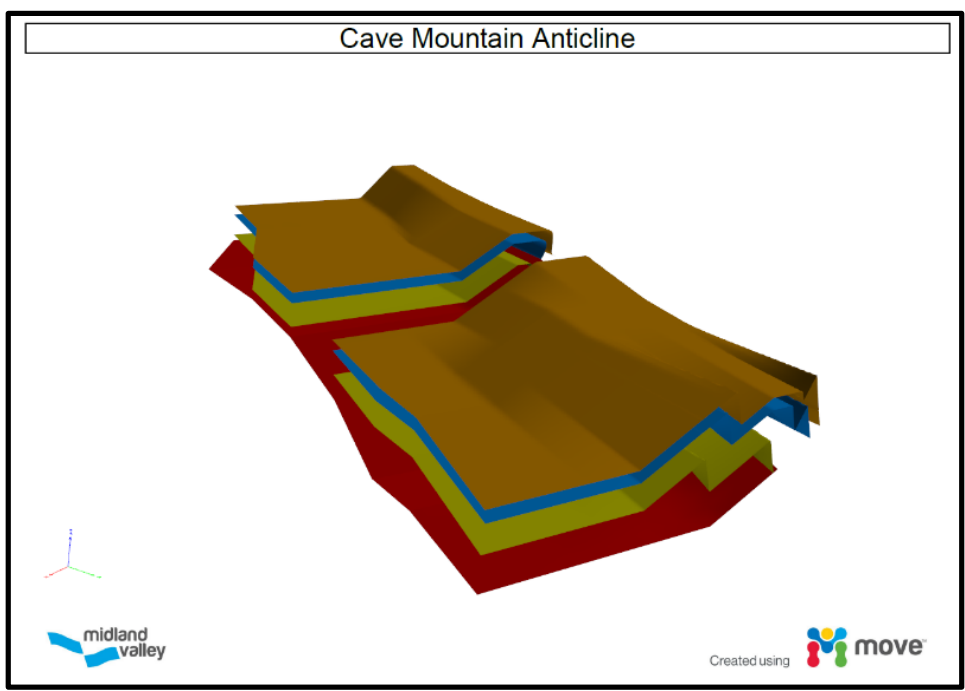

C
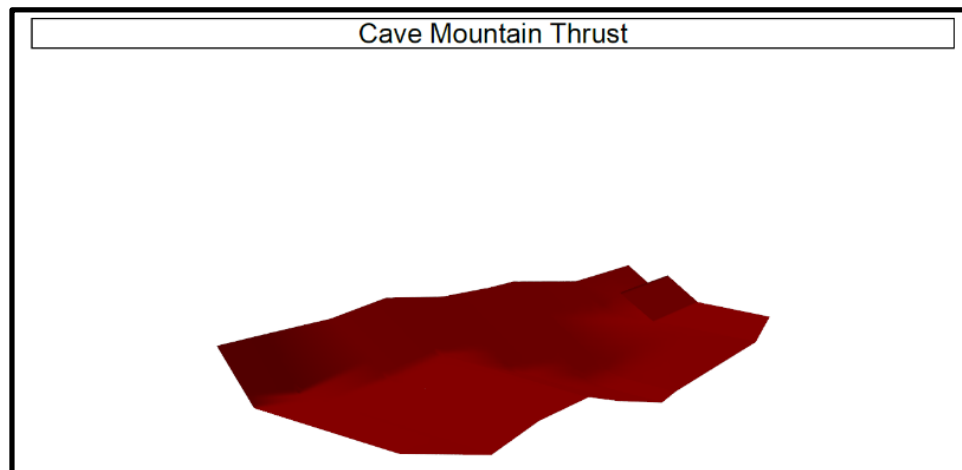

midland createdusing 8 move

Figure 23: Screenshots of the 3D structural model PDF exports. (A) Cave Mountain Anticline looking north, (B) Cave Mountain Anticline looking south, (C) Cave Mountain Thrust looking north. Red: thrust surface; Yellow: Tuscarora surface; Blue: Tonoloway surface; Orange: Oriskany surface. 


\section{Conclusions}

\section{Advantages of 3D mapping with Lidar}

Traditional 2D geological mapping will always be hindered by the fact that geological structures are inherently 3D. With increases in publicly available Lidar data paired with modern structural mapping software (3DMOVE), Lidar DEM's have the potential to revolutionize the world of geologic mapping. The most obvious improvement of a 3D map versus the traditional 2D map is the dramatic advantage of the 3D viewer. 3D visualization of the aerial Lidar data increased our confidence in structural measurements and observations, map accuracy, and geometric interpretation. The ability to see and map the 3D geometry of a broad, largely inaccessible and tree-covered structure such as the Cave Mountain anticline, meant we could be confident that the geometric basis for our interpretations was real and not affected by errors in field mapping (inaccurate sketches, inferred contacts in covered or inaccessible areas). Additionally, by following bedding traces when mapping contacts, line work represents actual contact geometry. At the Smoke Holes, this was evident for contacts on the anti-dip slope of Cave Mountain, which were originally drawn with curved lines when in fact many of them have sharp edges and corners. Another advantage is the information gained in high-relief areas. In a 2D map view, a structural feature at the base of a cliff will be foreshortened or may be hidden amongst a cluster of contact and contour lines. The map by Gerritsen (1988) for example, uses $400 \mathrm{ft}$ contours to minimize the amount of clutter in map view. Furthermore, Gerritsen (1988) chose to ignore small but significant structural features in order to minimize line work, such as the back-thrust present at Big Bend Campground in figure 24. Even draping a 2-D map over the DEM (2.5-D) presents its own issues, such as pixel smear on steep landscapes. Through 3D mapping, we were able to limit or eliminate the loss of structural information in these high relief areas. 
Lastly, as many geologists have already realized, the logistics and costs of fieldwork can be expensive, and remote field areas require that key structural features be recognized and mapped on the first field excursion. Lidar DEMs allow the geologist to revisit any geologic feature numerous times, from several angles, illuminated with a lighting of their choosing.

Until recently, the largest obstacle for widespread use of Lidar DEMs has been the costs associated with data collection and the often rigorous post-collection processing required to remove the forest canopy and other non-ground returns. However, thanks to programs such as the USGS 3D Elevation Program (3DEP) which have been developed to respond the growing need for highquality topographic data, nation-wide Lidar coverage at 1-m resolution will soon be available to the public. By combining these publicly available DEMs with modern structural modeling toolkits like MOVE, large amounts of structural data may be rapidly gathered on bed rock structure. Extracted bedding orientation data and exposed formation contacts can be used to verify older maps, test existing interpretations, and create new high-resolution 3D maps. In the long term we predict a national database of 3D geological maps, which can be readily shared and viewed in 3D with free interactive platforms such as Google Earth. 


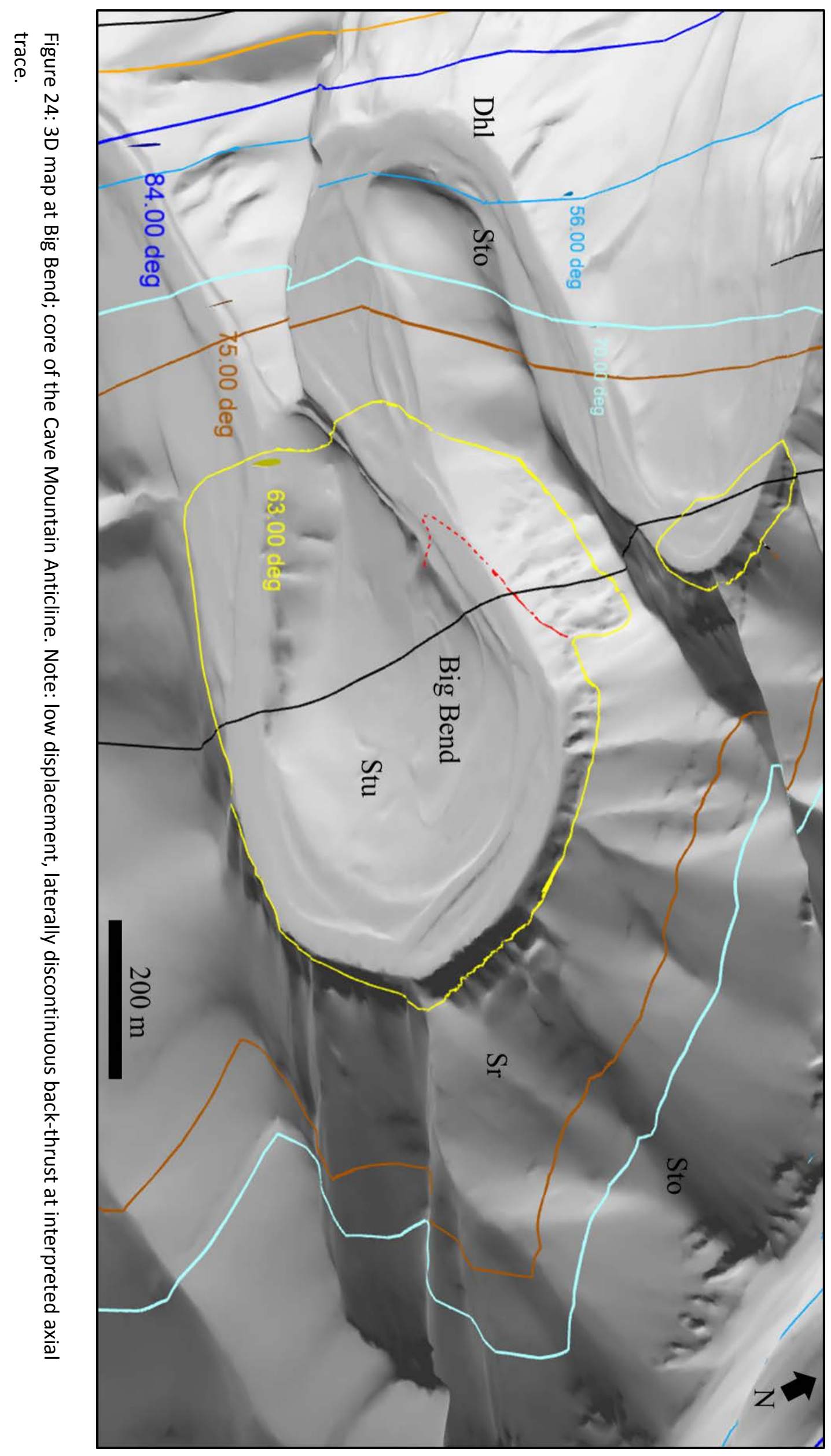




\section{Insights gained from the 3D Structural Model of the Smoke Hole}

The combination of the 3D model with the Lidar DEM allows for an interesting comparison between the actual locations of outcrop exposures and the ones predicted by the model. The best example is the Tuscarora formation, which has only been mapped along the river at Big Bend and nearby cut banks. By overlaying the 3D Tuscarora surface generated from our cross sections over the DEM (figure 25) we could accurately predict where the Tuscarora should be present in outcrop. Comparison of the outcrop prediction to the 2D map and 3D map allowed us to confirm that the formation had been mapped accurately and provided some verification for the accuracy of the model. In other contexts, we predict that the 3D model could be used to correct errors in geologic maps by quickly illustrating where specific formations should intersect with the surface.

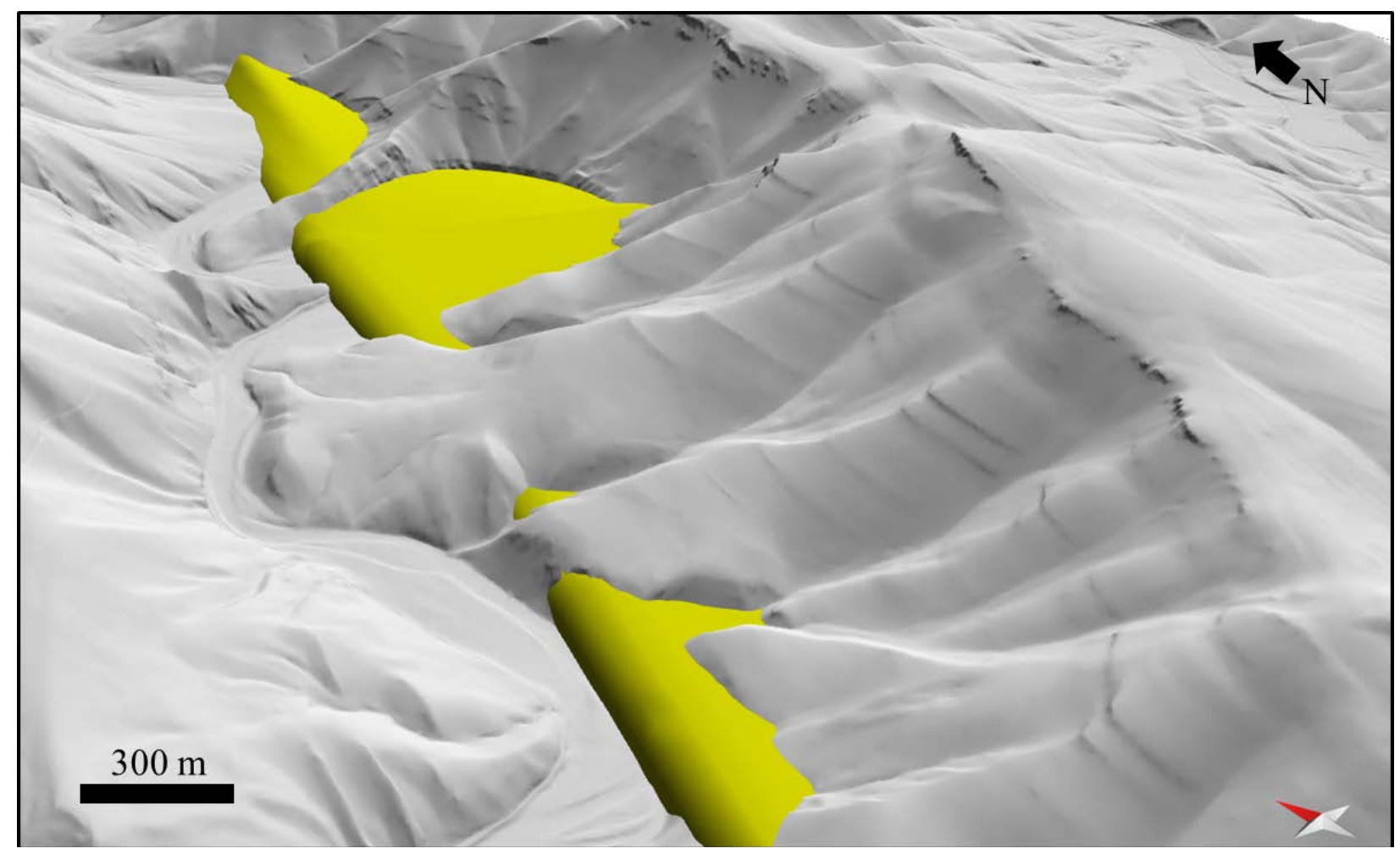

Figure 25: Outcrop prediction utilizing the 3D model with high-resolution Lidar. (Yellow: Tuscarora surface generated from 2D Kinematic models. 
However, although we were able to generate this 3D visualization of the Cave Mountain Anticline though linked cross sections, it is important to recognize that the model is still a simplification of nature and there were structural components we were not able to account for. As we lacked any subsurface data, using the kinematic models to develop our cross sections was essential for learning about how deformation extends in to the subsurface, and for making specific interpretations and estimates on fault geometry, amount of slip, and depth to detachment. Because the model is built on these linked kinematically modeled cross sections which use simple, straight and curved lines to create balanced structures, it was unable to perfectly match the 3D geometry of some of the structures revealed by the Lidar. For example, small and laterally discontinuous structures, such as the back thrust at Big Bend (Fig 24), were impossible to implement with the Trishear algorithm. This apparent component of backshear, along with the simplifications of the kinematic modules, creates small mismatches between the model and reality, and shows that the Trishear algorithm does not work for a certain level of structural complexity. For this reason, we place an emphasis on the fact that the 3D structural model should be viewed as a learning tool and a way to visualize the shape of the fold and fault in 3D, rather than taken as an exact replica of the structure.

Another implication of this study is that, when combined with structural modeling software such as MOVE, Lidar DEM's have enormous potential as a teaching and learning tool. In structural courses, understanding and visualizing the 3D nature of bedding planes, folds, and faults, is often a source of confusion among students. Students may have further trouble understanding important concepts such as the rule of V's (Fig 26) and 3D geometry of folds and faults when they are taught using 2D maps or simplified block models. Although these techniques may effective for the more adept students, many students often struggle when it comes time to 
transfer these concepts to actual field mapping. By pairing high resolution Lidar DEM's with structural software such as MOVE, students can practice common field mapping techniques in a lab setting. These lab sessions can then be supplemented with field excursions, allowing students to compare their DEM line work with true fieldwork. Furthermore, the Lidar DEM can provide an alternative for institutions that are located far from adequate field areas. In the future, we predict that 3D techniques will become more commonplace through improvements and increases in the availability of these high-resolution Lidar DEM's. 


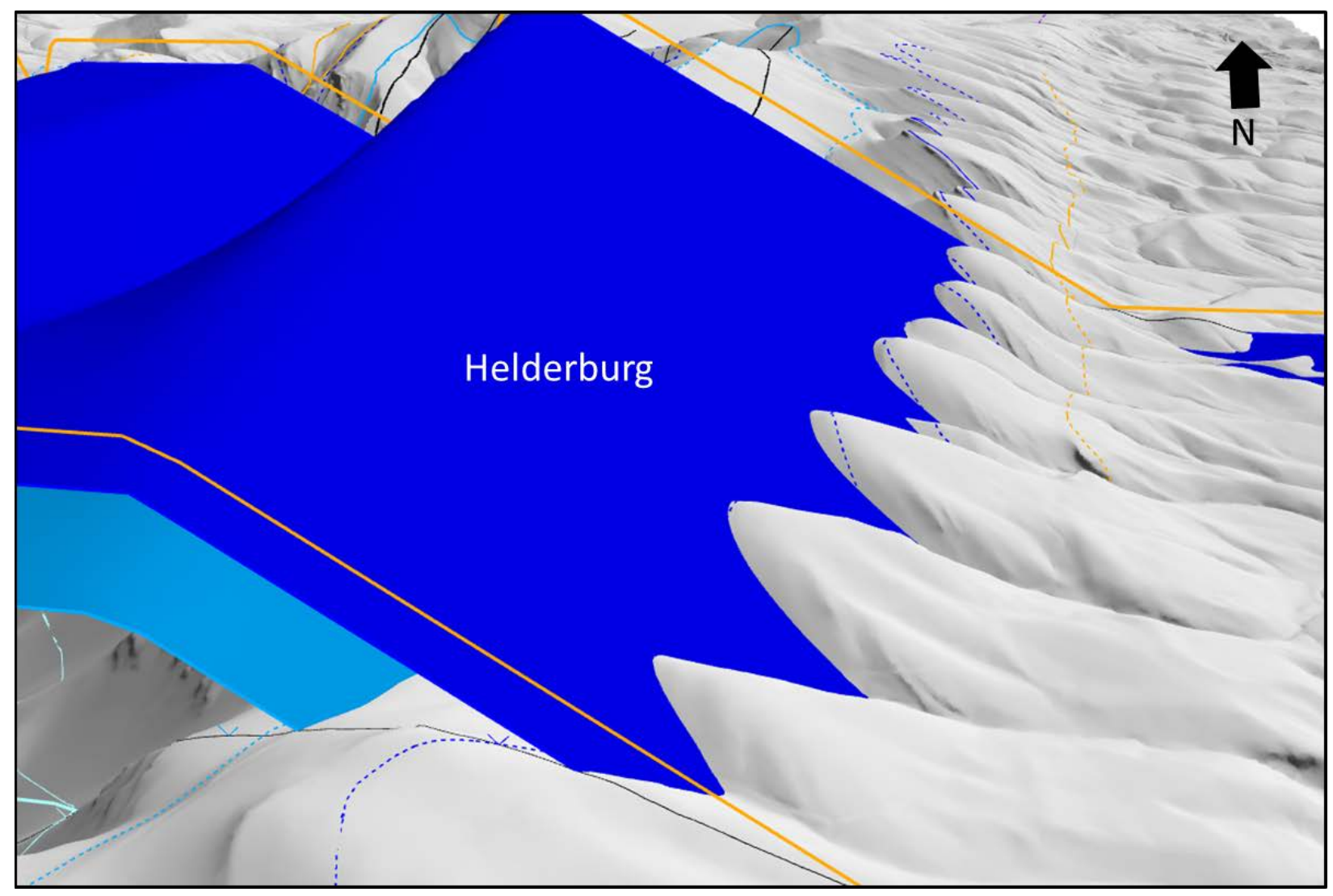

Figure 26: 3D model illustrating the rule of V's on the backlimb of the Cave Mountain anticline. (Orange: top Oriskany horizon; dark blue: top of Helderburg; light blue: top of Tonoloway) 


\section{References}

Arrowsmith, J. R., \& Zielke, O. (2009). Tectonic geomorphology of the San Andreas fault zone from high resolution topography: An example from the Cholame segment. Geomorphology, 113(1-2), 70-81.

Allmendinger, R. W. (1998). Inverse and forward numerical modeling of Trishear faultpropagation folds. Tectonics, 17(4), 640-656. doi:10.1029/98tc01907

Ardizzone, F., Cardinali, M., Galli, M., Guzzetti, F., \& Reichenbach, P. (2007). Identification and mapping of recent rainfall-induced landslides using elevation data collected by airborne Lidar. Natural Hazards and Earth System Science, 7(6), 637-650.

Blaszczynski, J.S., (1997) Landform characterization with Geographic Information Systems. Photogrammetric Engineering and Remote Sensing, 63(2):183-191.

Bellian, J. A., Kerans, C., \& Jennette, D. C. (2005). Digital outcrop models: applications of terrestrial scanning Lidar technology in stratigraphic modeling. Journal of sedimentary research, 75(2), 166-176.

Berry, J. K. 2002. Use surface area for realistic calculations. Geoworld 15(9): 20-1.

Kulander, B. R., \& Dean, S. L. (1986). Structure and Tectonics of Central and Southern Appalachian Valley and Ridge and Plateau Provinces, West Virginian and Virginia. AAPG Bulletin, 70(11), 1674-1684.

Dunne, W. M. (1996). The role of macroscale thrusts in the deformation of the Alleghanian roof sequence in the Central Appalachians; a re-evaluation. American Journal of Science, 296(5), 549-575. doi:10.2475/ajs.296.5.549

Dunne, W. M. (1986). Mesostructural Development in Detached Folds: An Example from West Virginia. The Journal of Geology, 94(4), 473-488. doi:10.1086/629052 
Erslev, E. A. (1991). Trishear fault-propagation folding. Geology, 19(6), 617. doi:10.1130/00917613(1991)019<0617:tfpf>2.3.co;2

Evans JS, Oakleaf J, Cushman SA, Theobald D (2014) An ArcGIS Toolbox for Surface Gradient and Geomorphometric Modeling, version 2.0-0.

Hardy, S., \& Ford, M. (1997). Numerical modeling of Trishear fault propagation folding. Tectonics, 16(5), 841-854.

Jamison, W. R. (1987). Geometric analysis of fold development in overthrust terranes. Journal of Structural Geology, 9(2), 207-219. doi:10.1016/0191-8141(87)90026-5

Johnson, K. M., \& Johnson, A. M. (2002). Mechanical models of Trishear-like folds. Journal of Structural Geology, 24(2), 277-287.

Mitra, S. (2003). A unified kinematic model for the evolution of detachment folds. Journal of Structural Geology, 25(10), 1659-1673. doi:10.1016/s0191-8141(02)00198-0

Pavlis, T. L., \& Bruhn, R. L. (2010). Application of LIDAR to resolving bedrock structure in areas of poor exposure: An example from the STEEP study area, southern Alaska. Geological Society of America Bulletin, 123(1-2), 206-217. doi:10.1130/b30132.1

Pavlis, T. L., \& Mason, K. A. (2017). The New World of 3D Geologic Mapping. GSA Today, 410. doi:10.1130/gsatg313a.1

Pei, Y., Paton, D. A., \& Knipe, R. J. (2014). Defining a 3-dimensional Trishear parameter space to understand the temporal evolution of fault propagation folds. Journal of structural Geology, 66, 284-297.

Pike, R. J., Evans, I. S., \& Hengl, T. (2009). Geomorphometry: a brief guide. Developments in Soil Science, 33, 3-30. 
Riley, S. J., S. D. DeGloria and R. Elliot (1999). A terrain ruggedness index that quantifies topographic heterogeneity. InterMountain Journal of Sciences, 5(1-4)

Sithole, G., \& Vosselman, G. (2004). Experimental comparison of filter algorithms for bareEarth extraction from airborne laser scanning point clouds. ISPRS Journal of Photogrammetry and Remote Sensing, 59(1-2), 85-101. doi:10.1016/j.isprsjprs.2004.05.004

West Virginia Geological and Economic Survey, “Geologic Map of West Virginia”, Map 25A, March 2011

Wozencraft, J., \& Millar, D. (2005). Airborne Lidar and integrated technologies for coastal mapping and nautical charting. Marine Technology Society Journal, 39(3), 27-35.

Zhang, K., Chen, S., Whitman, D., Shyu, M., Yan, J., \& Zhang, C. (2003). A progressive morphological filter for removing nonground measurements from airborne LIDAR data. IEEE Transactions on Geoscience and Remote Sensing, 41(4), 872-882. doi:10.1109/tgrs.2003.810682

Zhang, K., Yan, J., \& Chen, S. C. (2006). Automatic construction of building footprints from airborne LIDAR data. IEEE Transactions on Geoscience and Remote Sensing, 44(9), 2523-2533. 
Appendix

Fold Parameters:

\section{Cave Mountain Anticline Parameters}

\begin{tabular}{|c|c|c|c|c|}
\cline { 2 - 4 } \multicolumn{4}{c|}{ CMA - Big Bend } & \multicolumn{1}{c|}{} \\
\hline Stage & Movement & P/S Ratio & Trishear Angle & $\begin{array}{c}\text { Angle } \\
\text { offset }\end{array}$ \\
\hline 1 & $600 \mathrm{~m}$ & 1.25 & 65 & 0.6 \\
\hline 2 & $600 \mathrm{~m}$ & 1.25 & 60 & 0.6 \\
\hline 3 & $600 \mathrm{~m}$ & 1.25 & 55 & 0.6 \\
\hline
\end{tabular}

\begin{tabular}{|c|c|}
\hline \multicolumn{2}{|c|}{ CMA - F-F' } \\
\hline Apical angle & 60 \\
\hline Angle offset & 0.6 \\
\hline P/S ratio & 1.25 \\
\hline Ramp angle & 30 \\
\hline Movement & $1300 \mathrm{~m}$ \\
\hline
\end{tabular}

\begin{tabular}{|c|c|}
\hline \multicolumn{2}{|c|}{ CMA - G-G' } \\
\hline Apical angle & 65 \\
\hline Angle offset & 0.6 \\
\hline P/S ratio & 1.25 \\
\hline Ramp angle & 30 \\
\hline Movement & $1100 \mathrm{~m}$ \\
\hline
\end{tabular}

\begin{tabular}{|c|c|}
\hline \multicolumn{2}{|c|}{ CMA - H-H' } \\
\hline Apical angle & 65 \\
\hline Angle offset & 0.5 \\
\hline P/S ratio & 1.25 \\
\hline Ramp angle & 45 \\
\hline Movement & $900 \mathrm{~m}$ \\
\hline
\end{tabular}




CMA - North

\begin{tabular}{|c|c|}
\hline \multicolumn{2}{|c|}{ Western Thrust (main) } \\
\hline Movement & $580 \mathrm{~m}$ \\
\hline Ramp angle & 30 \\
\hline
\end{tabular}

\begin{tabular}{|c|c|}
\hline \multicolumn{2}{|c|}{ Eastern Thrust } \\
\hline Movement & $500 \mathrm{~m}$ \\
\hline Ramp angle & 30 \\
\hline
\end{tabular}

\section{Detachment Fold Parameters}

\begin{tabular}{|c|c|}
\hline \multicolumn{2}{|c|}{ Big Bend 2 } \\
\hline \multicolumn{2}{|c|}{ PCA } \\
\hline Movement & $200 \mathrm{~m}$ \\
\hline Forelimb ratio & 0.6 \\
\hline Mode & Constant Area \\
\hline $\begin{array}{c}\text { Ductile } \\
\text { Thickness }\end{array}$ & $200 \mathrm{~m}$ \\
\hline
\end{tabular}

\begin{tabular}{|c|c|}
\hline \multicolumn{2}{|c|}{ Big Bend 1 } \\
\hline \multicolumn{2}{|c|}{ PCA } \\
\hline Movement & $300 \mathrm{~m}$ \\
\hline Forelimb ratio & 0.8 \\
\hline Mode & Constant Area \\
\hline Ductile Thickness & $200 \mathrm{~m}$ \\
\hline
\end{tabular}

\section{Thrust faults}

\begin{tabular}{|c|c|}
\hline \multicolumn{2}{|c|}{ Eagle Rock Thrust } \\
\hline P/S ratio & 1.5 \\
\hline Apical angle & 50 \\
\hline angle offset & 0.5 \\
\hline Movement & $120 \mathrm{~m}$ \\
\hline
\end{tabular}

\begin{tabular}{|c|c|}
\hline \multicolumn{2}{|c|}{ Mapledale Thrust } \\
\hline Ramp angle & 30 \\
\hline Movement & $60 \mathrm{~m}$ \\
\hline
\end{tabular}


Additional Cross Sections

A-A'

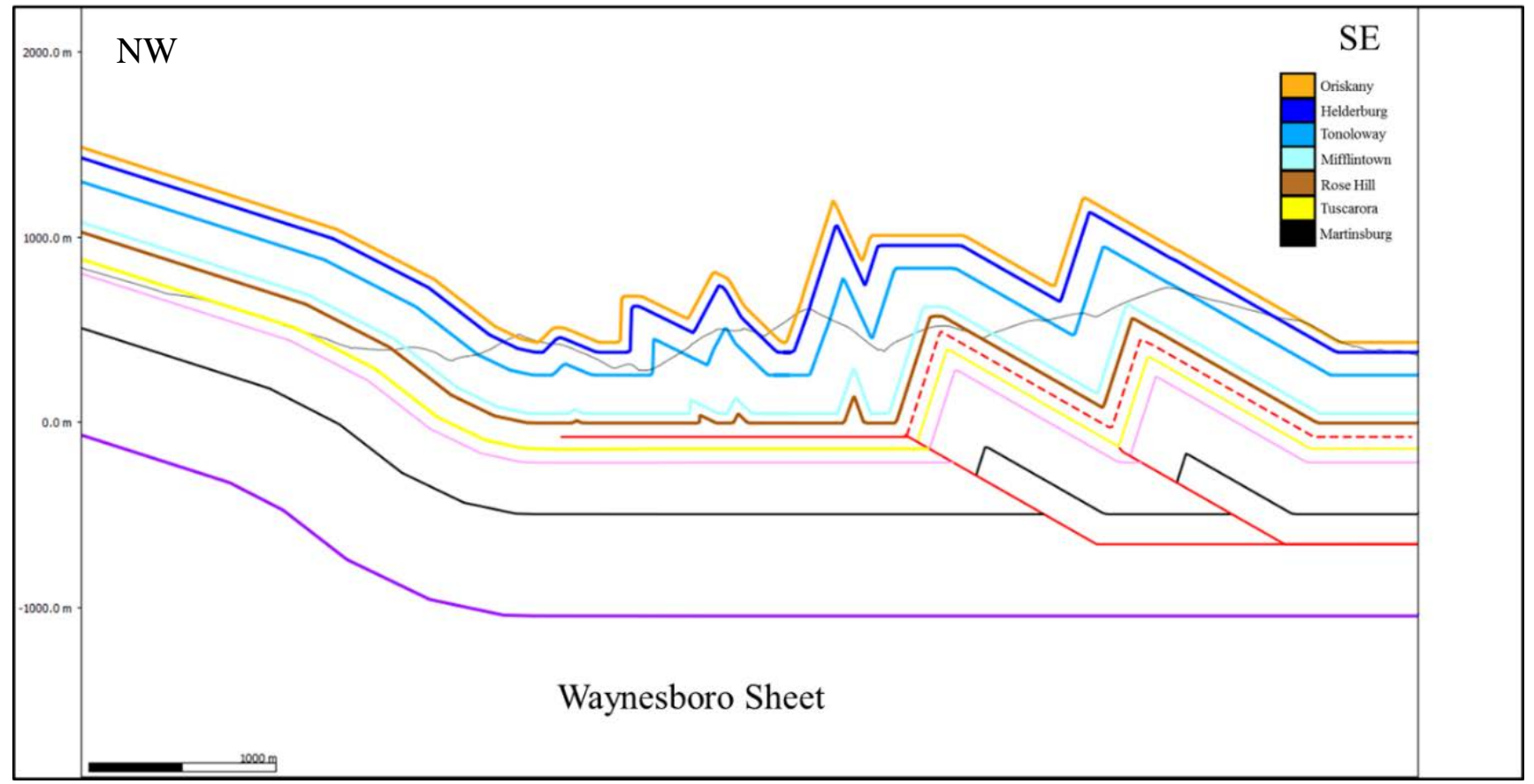

C-C’

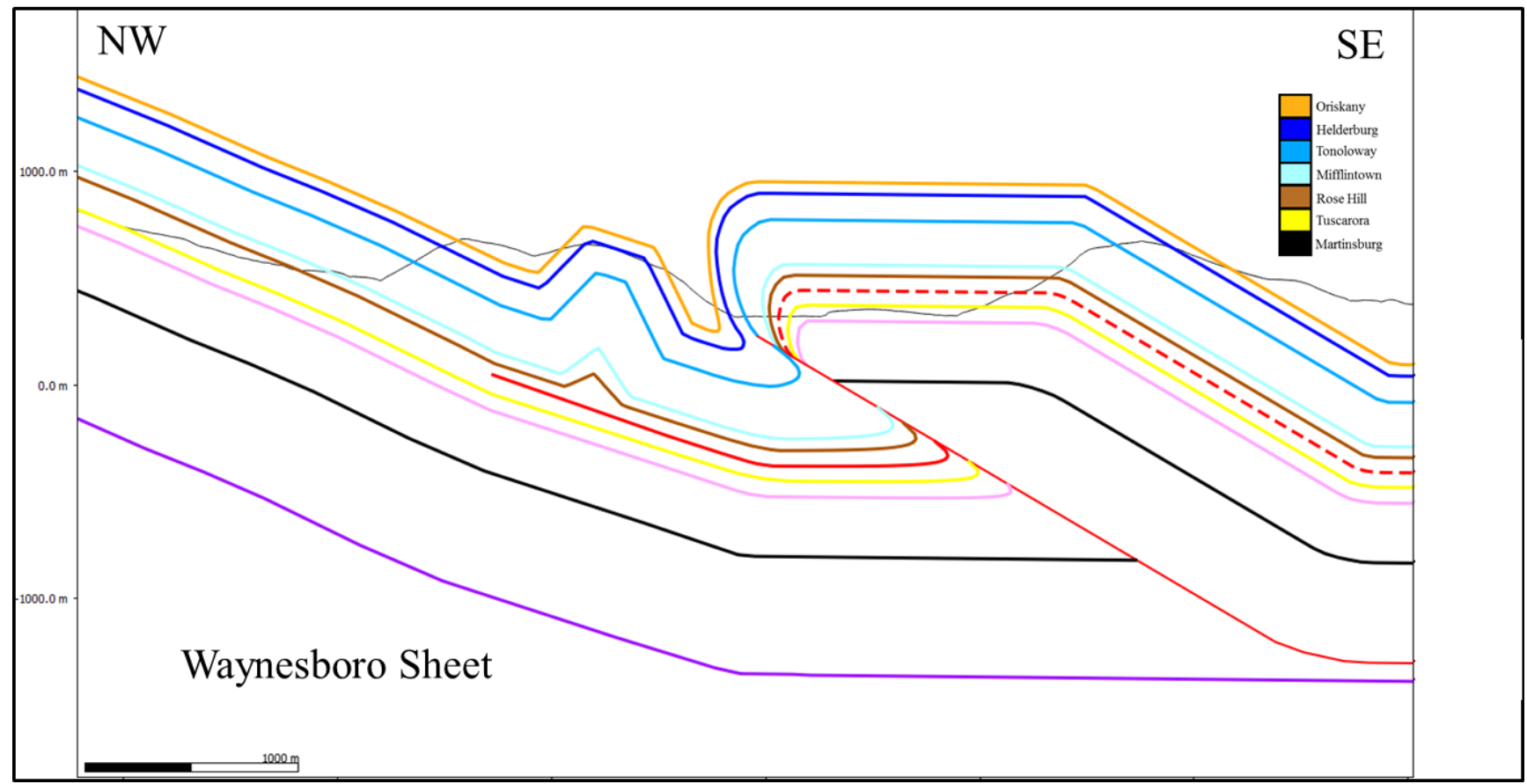




\section{E-E'}

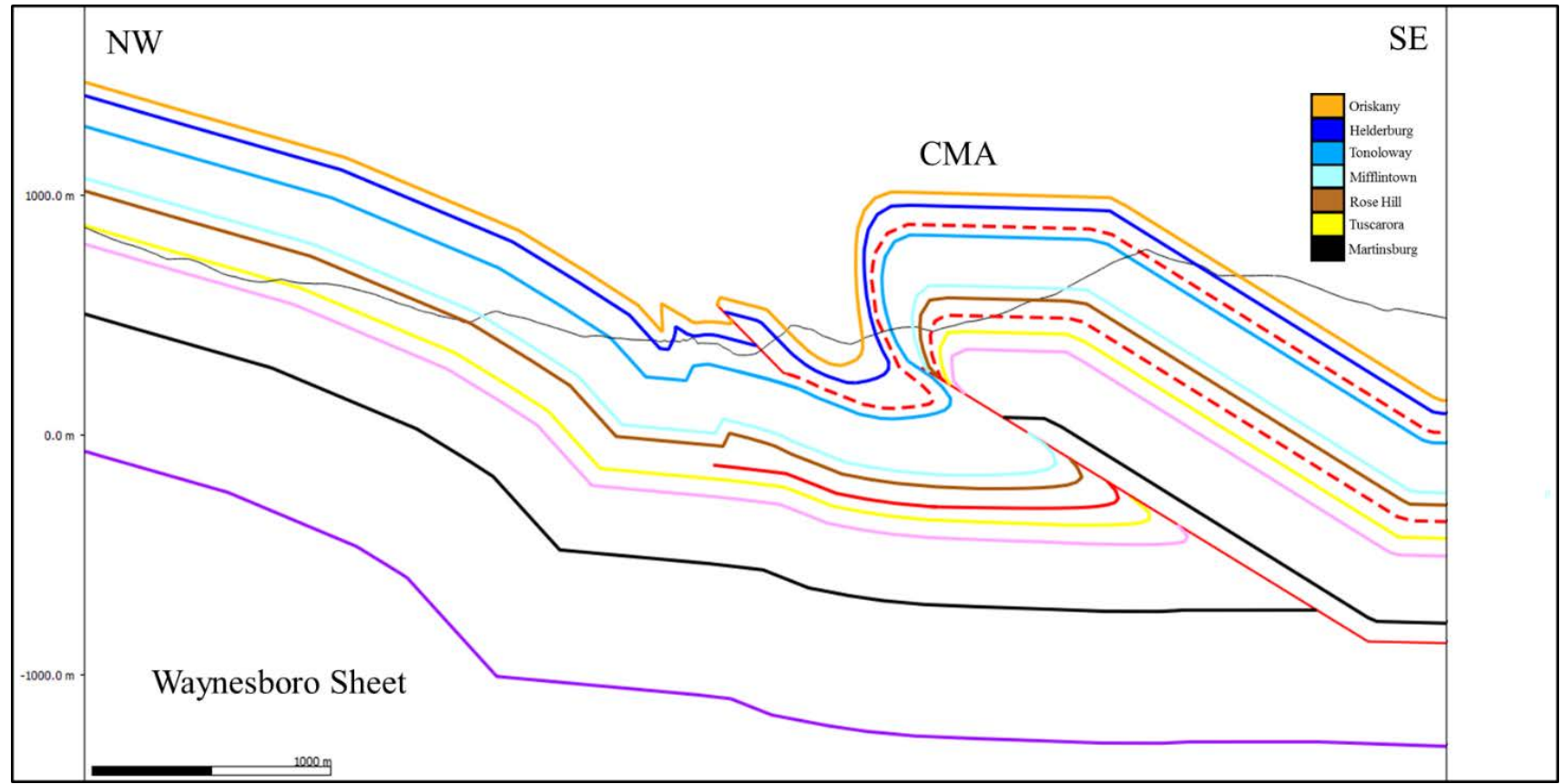

F-F'

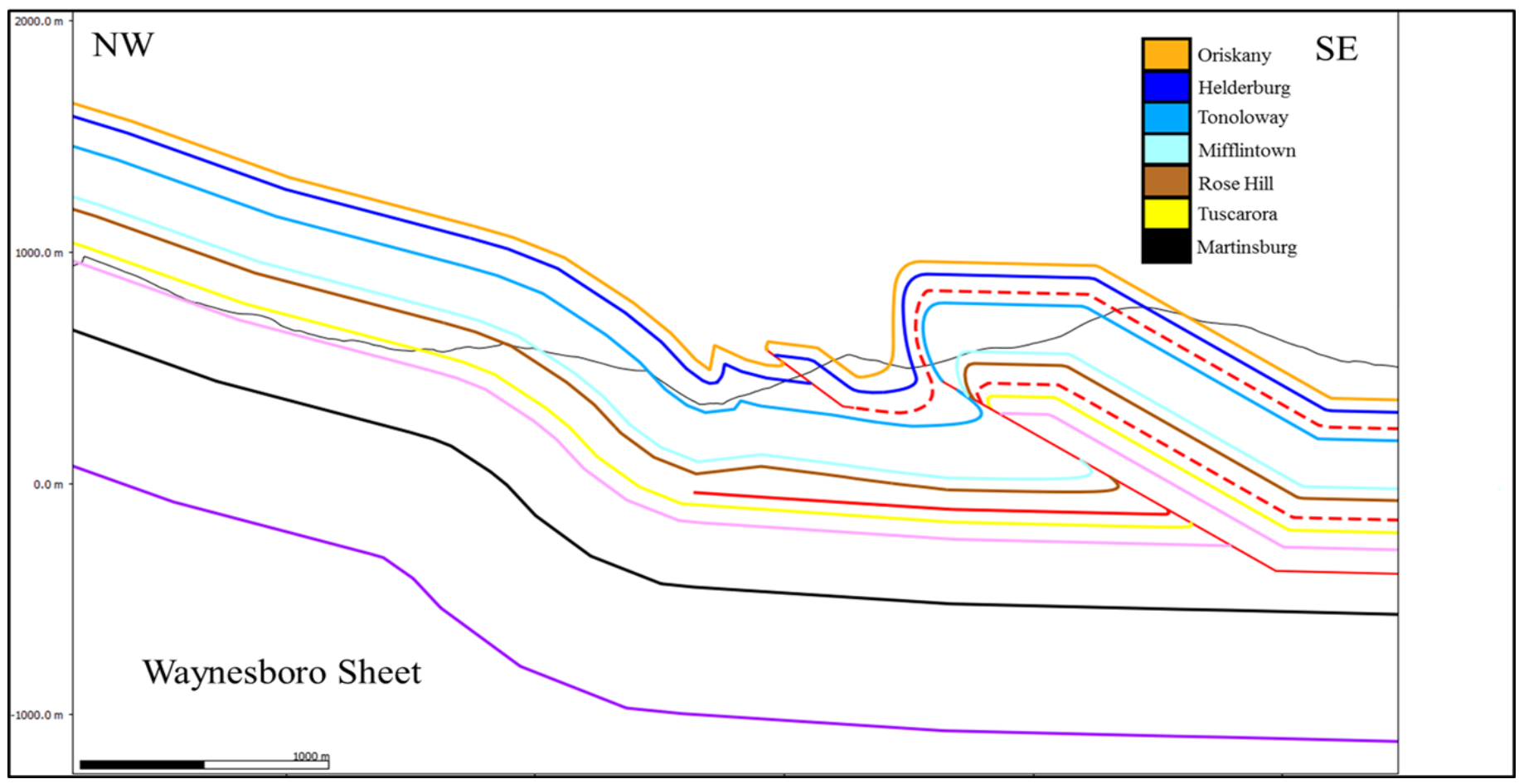




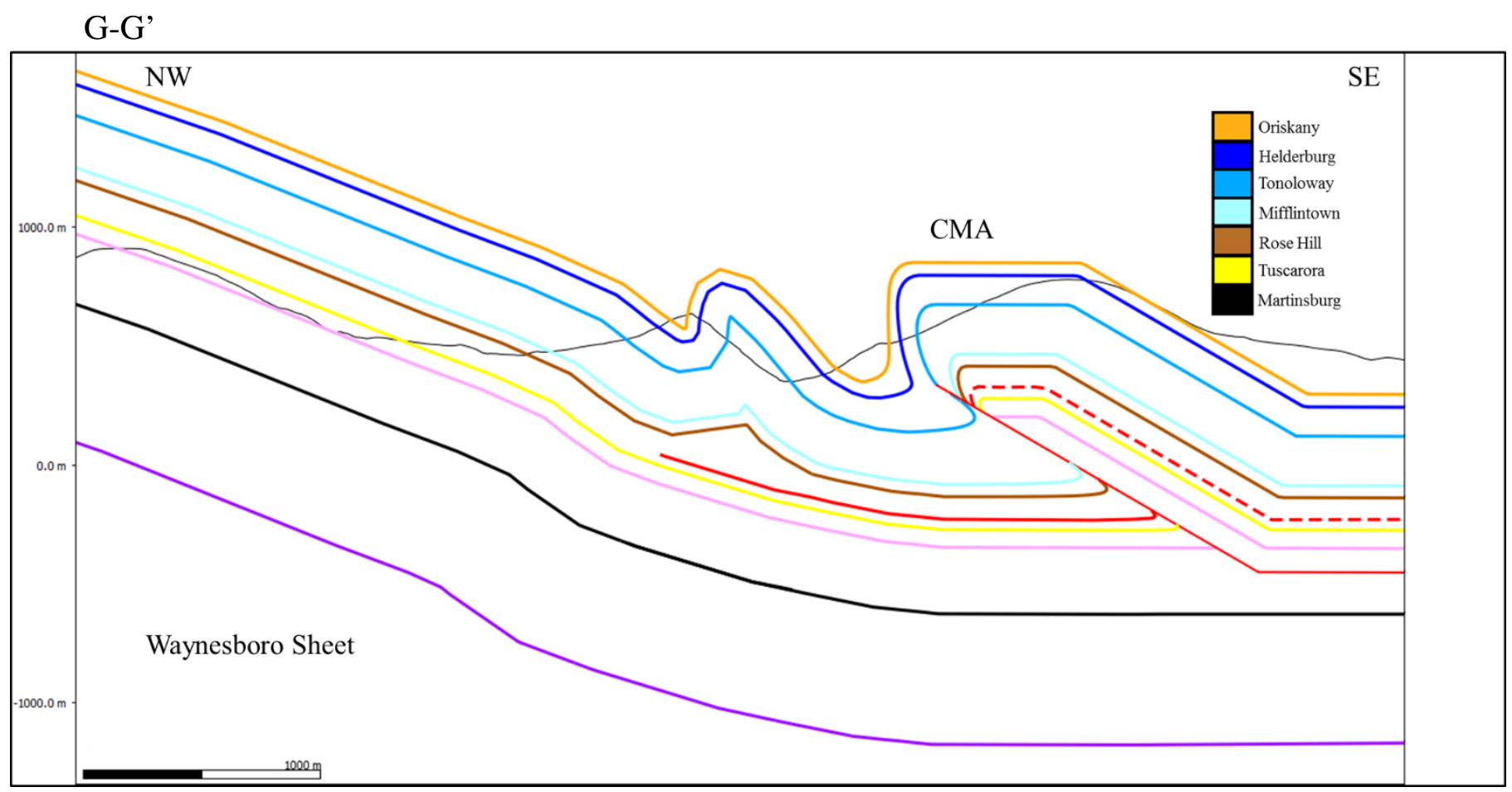

H-H'

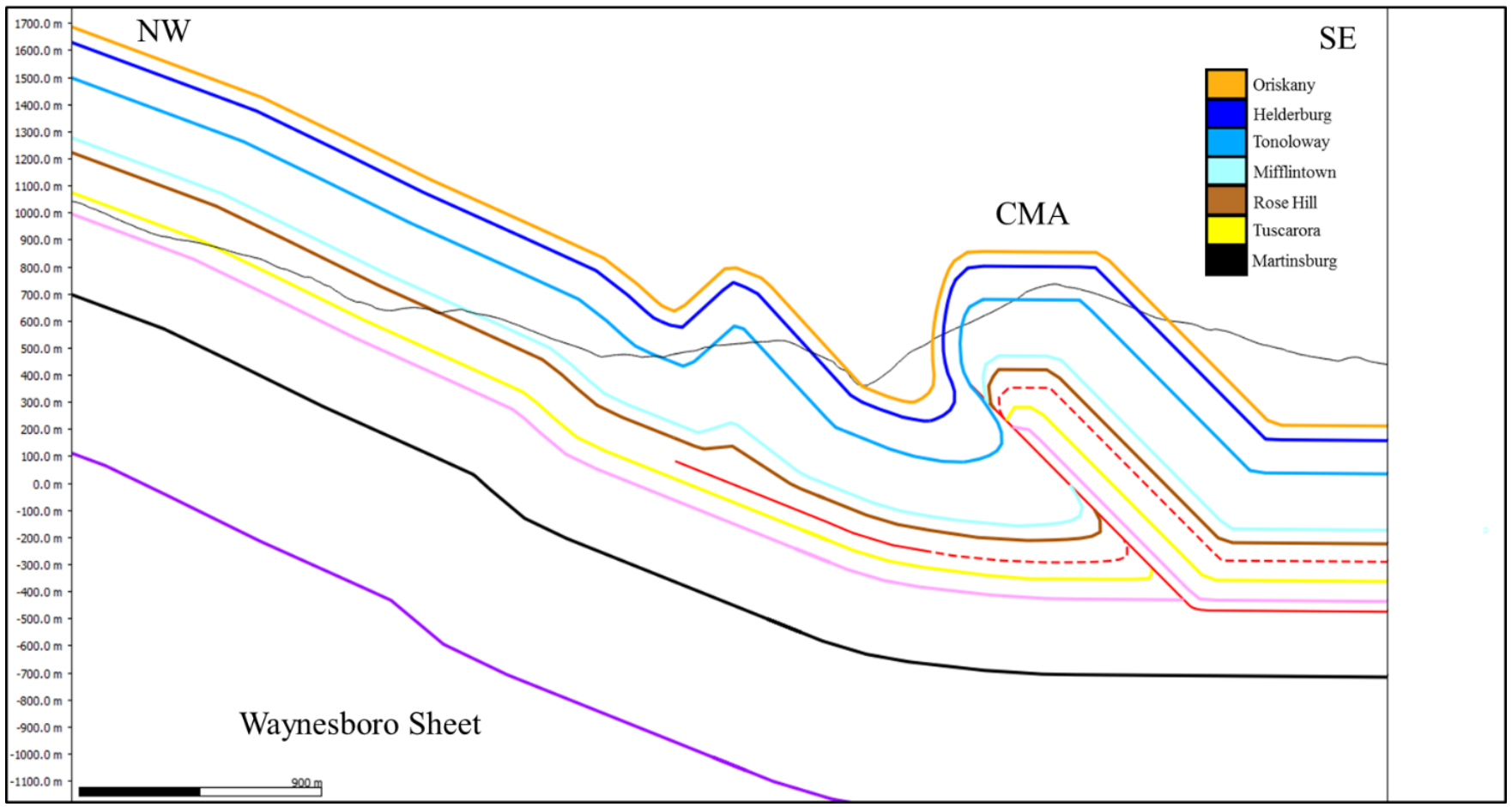


